\title{
Three hallmarks of malaria-induced selection in human genomes
}

${ }^{1}$ Harvard T.H. Chan School of Public Health, Boston, MA USA

Abstract

9 Malaria has plausibly been the single strongest selective pressure on our species. Many

10 of the best-characterized cases of adaptive evolution in humans are in genes tied to

11 malaria resistance. However, the complex evolutionary patterns at these genes are poorly

12 captured by standard scans for non-neutral evolution. Here we present three new

13 statistical tests for selection based on population genetic patterns that are observed more

14 than once among key malaria resistance loci. We assess these tests using forward-time

15 evolutionary simulations and apply them to global whole-genome sequencing data from

16 humans, and thus we show that they are effective at distinguishing selection from

17 neutrality. Each test captures a distinct evolutionary pattern, here called Divergent

18 Haplotypes, Repeated Shifts, and Arrested Sweeps, associated with a particular period of

19 human prehistory. We clarify the selective signatures at known malaria-relevant genes

20 and identify additional genes showing similar adaptive evolutionary patterns. Among our 
21 top outliers, we see a particular enrichment for genes involved in erythropoiesis and for

22 genes previously associated with malaria resistance, consistent with a major role for

23 malaria in shaping these patterns of genetic diversity. Polymorphisms at these genes are

24 likely to impact resistance to malaria infection and contribute to ongoing host-parasite

25 coevolutionary dynamics.

27 Introduction spread by mosquitoes, has been one of the most important selective pressures on the

30 human lineage (Ebel et al. 2017). Bolstered by the intimate coevolutionary history between

31 humans and Plasmodium and the severe pathology of malaria, several of the strongest

32 signatures of selection in the human genome center on genes that impact malaria

33 resistance. These genes include $A B O$ (A/B/O blood group; Ségurel et al. 2012, 2013), the

34 cluster of GYPA, GYPB, and GYPE (here abbreviated to GYPA/B/E, glycophorin Dantu blood

35 group; Leffler et al. 2017), ACKR1 (Duffy antigen; Hamblin et al. 2002; King et al. 2011;

36 Chittoria et al. 2012), CR1 (Knops blood group; Tham et al. 2010; Prajapati et al. 2019),

$37 H B B$ (hemoglobin B; Allison 1954; Laval et al. 2019), and G6PD (glucose-6-phosphate

38 dehydrogenase; Ruwende et al. 1995; Tishkoff et al. 2001). Malaria remains a major

39 selection pressure to this day, with 200 million cases annually, leading to over 400,000

40 deaths (Miller et al. 2002; WHO 2019). 
The adaptive signatures wrought by Plasmodium on humans are useful to

42 characterize and study, for two reasons. First, evolutionary signatures have been critical

43 for finding new malaria-relevant genes ( $H B B$, Allison 1954; GYPA/B/E, Malaria Genomic

44 Epidemiology Network 2015). There are likely more large-effect genes to be found, as

45 over half of the heritability in malaria resistance ( $h^{2} \sim 24 \%$ ) remains unexplained

46 (Mackinnon et al. 2005; Malaria Genomic Epidemiology Network 2019) and there is

47 substantial geographic heterogeneity in the genetic basis of resistance (Leffler et al. 2017).

48 Progress toward malaria elimination has stalled in recent years, prompting the need for

49 new treatments (White et al. 2014; WHO 2019). Understanding the genetic basis of malaria

50 resistance can pave the way for therapeutics that target host-parasite molecular

51 interactions (Cowman et al. 2017) and inform precision medicine. Second, malaria

52 resistance genes present a robust model system to develop and assess statistical tests for

53 selection, given their striking evolutionary signatures and well-documented phenotypic

54 effects (Malaria Genomic Epidemiology Network 2019). Such tests may be broadly

55 applicable to study other selective pressures, for example in other host-parasite systems.

56 Genome-wide scans for selection in humans are now routine (Fan et al. 2016), but

57 they have poor replicability such that different methods produce very different lists of

58 candidate genes. This is true for positive selection (Akey 2009) and may be worse for

59 balancing selection: among six recent studies that scan the genome for balancing

60 selection in Africans or African Americans, the proportion of identified candidate selection 
61 targets that are shared between any two scans ranges from 0 to 9\% (Andrés et al. 2009;

62 Leffler et al. 2013; DeGiorgio et al. 2014; Siewert and Voight 2017; Bitarello et al. 2018;

63 Cheng and DeGiorgio 2019). For some genes, selection has been effectively validated

64 phenotypically because allelic effects on infection or fitness have been demonstrated.

65 However, while these known causal genes (e.g. $H B B, A B O, G 6 P D$ ) do show unusual and

66 presumably non-neutral population genetic patterns, they overlap poorly with genome-

67 wide selection scans, suggesting that existing tests are underpowered to detect true

68 positives. There is both a need for analytical tools that can better distinguish biologically

69 meaningful polymorphism from neutral polymorphism, and an opportunity to leverage

70 these functionally validated loci to guide the development of such tools.

71 In this paper, we focus on three population genetic patterns that are common in

72 malaria-relevant genes but are poorly approximated by existing statistical tests for

73 selection (Table 1; Figure 1). We call these patterns Divergent Haplotypes, Repeated Shifts,

74 and Arrested Sweeps. Each is represented by two exemplar loci (Table 1). We develop new

75 ways to summarize population genetic data that readily distinguish these signatures from

76 the neutral background, and assess these statistics using simulations. In order to diversify

77 the character set for population genetics beyond the heavily used Latin and Greek

78 alphabets, each statistic is denoted by an emoji, as these Unicode characters are now a

79 standard component of publishing software and have been underutilized in science

80 (O’Reilly-Shah et al. 2018): Dango (\&), Trident ( $\Psi$ ), and Pause ( II ). Finally, we apply our 
81 tests to population genomic data (1000 Genomes Project Consortium 2015) to evaluate

82 their ability to detect known malaria-relevant genes and to identify new candidate genes.
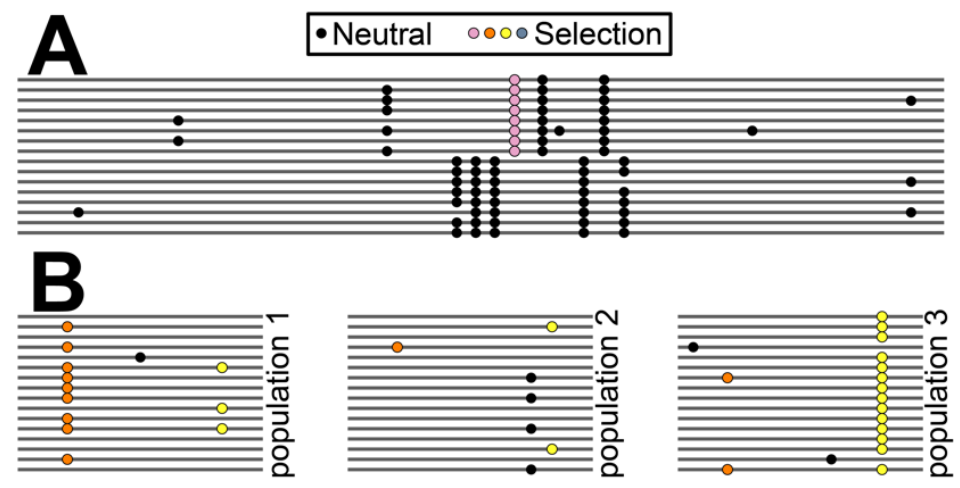

85 Figure 1. Three complex adaptive scenarios observed repeatedly among malaria-relevant genes. Lines

86 represent chromosomes. Circles are derived alleles at polymorphic sites (black = neutral; colored =

87 adaptive). (A) Divergent Haplotypes. A dense cluster of variants in high linkage disequilibrium occurs within

88 a narrow genomic window surrounding a balanced polymorphism. (B) Repeated Shifts. All three pairwise

89 population comparisons show unusually high divergence at one or more variants, suggesting repeated

90 bouts of positive selection. (C) Arrested Sweep. A beneficial mutation swept up a long haplotype but

91 stopped at relatively low frequency.

92

93 Table 1. Framework for detecting three adaptive evolutionary scenarios

\begin{tabular}{|l|l|l|l|l|l|}
\hline Scenario & Pattern & Timescale & $\begin{array}{l}\text { Exemplar } \\
\text { Loci }\end{array}$ & $\begin{array}{l}\text { Best Existing } \\
\text { Statistic }\end{array}$ & $\begin{array}{l}\text { New } \\
\text { Statistic }\end{array}$ \\
\hline $\begin{array}{l}\text { Divergent } \\
\text { Haplotypes }\end{array}$ & $\begin{array}{l}\text { Variant clusters with } \\
\text { high pairwise linkage } \\
\text { disequilibrium }\end{array}$ & $\begin{array}{l}10^{7} \text { years } \\
\text { ago to } \\
\text { present }\end{array}$ & $\begin{array}{l}A B O, \text { GYPA/ } \\
\text { GYPB/ GYPE }\end{array}$ & (Kelly 1997) & \& \\
\hline
\end{tabular}




\begin{tabular}{|c|c|c|c|c|c|}
\hline $\begin{array}{l}\text { Repeated } \\
\text { Shifts }\end{array}$ & $\begin{array}{l}\text { Allele frequency shifts in } \\
\text { multiple independent } \\
\text { populations, yielding } \\
\text { high pairwise FST }\end{array}$ & $\begin{array}{l}10^{5} \text { to } 10^{4} \\
\text { years ago }\end{array}$ & $C R 1, A C K R 1$ & $\begin{array}{l}\text { Parallel FST } \\
\text { (Tennessen } \\
\text { and Akey } \\
2011 \text { ) }\end{array}$ & $\psi$ \\
\hline $\begin{array}{l}\text { Arrested } \\
\text { Sweep }\end{array}$ & $\begin{array}{l}\text { Long haplotypes for } \\
\text { only the selected allele, } \\
\text { low divergence among } \\
\text { populations, purifying } \\
\text { selection in outgroup }\end{array}$ & $\begin{array}{l}10^{4} \text { years } \\
\text { ago to } \\
\text { present }\end{array}$ & $H B B, G 6 P D$ & $\begin{array}{l}\mathrm{nS} \quad \text { (Ferrer- } \\
\text { Admetlla et al. } \\
2014)\end{array}$ & II \\
\hline
\end{tabular}

New Approaches 
110 al. 2018), unless they incorporate non-human polymorphism (Leffler et al. 2013; Chang

111 and DeGiorgio 2019). However, intraspecies haplotype structure alone may convey a

112 signal of selection if tested for directly (Figure 1A).

113 We developed and evaluated a new test for Divergent Haplotypes. Old, balanced

114 haplotypes accumulate mutations which are protected from genetic drift, leading to

115 increased sequence divergence between the haplotypes (Figure 1A). This pattern is

116 disrupted by recombination, so it can typically be observed only across small genetic

117 distances. Clusters of closely adjacent variants in high linkage disequilibrium (LD) and

118 similar minor allele frequencies (MAF) are thus a signature of balancing selection (Siewert

119 and Voight 2017), as envisioned by Kelly (1997) with the $Z_{n s}$ statistic. However, $Z_{n s}$ is highly

120 sensitive to individual rare variants, which will typically not show high LD with any other

121 variant. Rare variants may or may not be observed depending on stochasticity and sample

122 size, making $Z_{n s}$ a very noisy statistic. We therefore define a new test statistic which sums

123 across LD correlations rather than averaging them: \& (equation 3). For a target variant,

124 is the sum of LD correlations with all other variants within a distance of $g$ bp. Using

125 rare variants have a negligible effect, and the statistic is maximized if there are a large

126 number of variants within a narrow region in high LD with each other. There is no upper

127 limit to $\&$, and its typical range for a given population will depend on overall levels of

128 nucleotide diversity and LD. Therefore, unusual values of $\%$ are defined in comparison to

129 the genome-wide average. 
$131 \quad$ Repeated Shifts and $\boldsymbol{\Psi}$

132 Repeated Shifts are a form of parallel adaptive divergence, which occurs when

133 positive selection repeatedly causes rapid allele frequency change, resulting in high F ST

134 (defined here following Weir and Cockerham 1984), at the same locus in geographically

135 distinct populations (Figure 1B). High divergence between independent pairs of

136 populations is unlikely to occur more than once unless driven by natural selection

137 (Tennessen and Akey 2011). Notably, some of the strongest human instances of parallel

138 adaptive divergence occur in genes with large effects on malaria resistance. $A C K R 1$ is not

139 only the single most divergent gene between Africa and Europe, but it is also among the

140 most divergent genes between Europe and Asia. This is due to near-fixation of the Duffy-

141 null allele in sub-Saharan Africa, and independent selection for the Fy allele in Asia

142 (Hamblin et al. 2002; King et al. 2011; Chittoria et al. 2012). Similarly, CR1 is also divergent

143 in both Africa-Europe and Asia-Europe comparisons due to positive selection (Prajapati

144 et al. 2019). Our previous genome-wide scan for parallel adaptive divergence (Tennessen

145 and Akey 2011) sought repeated, phylogenetically independent shifts occurring at the

146 same single-nucleotide variant among a set of four populations. Such strict criteria miss

147 ACKR1 and CR1. These genes show changes at different variants in different population

148 comparisons, and these comparisons are nested rather than truly independent (i.e. high 
149 Africa v. Eurasia divergence at some variants, and high Africa/Europe v. Asia divergence

150 at other variants). A revised approach might have enhanced power to detect such cases.

151 We developed and evaluated a new test for Repeated Shifts. Our goal was to detect

152 narrow genomic windows showing unusually high $\mathrm{F}_{\mathrm{ST}}$ in all three pairwise comparisons

153 among three populations, at the same or different variants (Figure 1B). Such population

154 triplets are not phylogenetically independent as in Tennessen and Akey (2011), but they

155 cannot be explained without multiple bouts of positive selection. Our approach is based

156 on inversely ranking genomic windows of size $g$ bp based on $\mathrm{F}_{\mathrm{ST}}$ and finding windows in

157 which all three pairwise ranks are relatively extreme. Our test statistic $\Psi$ (equation 4) is a

158 squared average between the lowest $(L)$ and highest $(H) \mathrm{F}_{\mathrm{ST}}$ ranks scaled by the number

159 of windows examined, which approximates a p-value reflecting the probability of

160 observing the data if there is no parallel selection acting. However, even values of $\Psi$ that

161 are not individually significant may provide evidence for selection if they are among the

162 most extreme values in the genome.

164 Arrested Sweeps and II

165 The Arrested Sweep pattern is observed at HBB and G6PD. At both of these loci,

166 an allele protective against malaria arose in Africa 5-25 kya (Tishkoff et al. 2001; Shriner

167 and Rotimi 2018; Laval et al. 2019) and rapidly increased in frequency. At both loci, the

168 protective allele then stopped spreading and has been maintained at about 10\% 
169 frequency because it conveys a physiological disadvantage when

170 homozygous/hemizygous (Figure 1C). Because of the low frequency of the derived allele,

171 these genes are missed by selection scans that seek intermediate frequency alleles or high

172 intercontinental $\mathrm{F}_{\text {ST. }}$ Because the recent timescale has precluded the accumulation of

173 elevated nucleotide diversity or trans-species polymorphisms, these genes are missed by

174 scans for ancient haplotypes. Thus, despite being canonical examples of adaptive

175 polymorphism, these genes are almost never detected in genome-wide scans for partial

176 sweeps or balancing selection (e.g. Voight et al. 2006; Akey 2009; Andrés et al. 2009; Leffler

177 et al. 2013; DeGiorgio et al. 2014; Siewert and Voight 2017; Bitarello et al. 2018; Cheng

178 and DeGiorgio 2019).

179 We developed and evaluated a new test for Arrested Sweeps. This test seeks

180 recently arisen variants which are beneficial when heterozygous but strongly deleterious

181 otherwise, as with $H B B$ and G6PD (Figure 1C). This test is conducted on a single target

182 population. It also requires several other populations hypothesized to experience similar

183 selective pressures; along with the target population, these constitute the "ingroup".

184 Finally, it requires an "outgroup" population in which there is no heterozygote advantage

185 to the derived variant, only the deleterious effect (as with any population where malaria

186 does not occur). There are two evolutionary components of an Arrested Sweep: the sweep

187 (positive selection) and the arrest (balancing and purifying selection). 

signal of low polymorphism and long-range LD within the beneficial haplotypic lineage,

191 However, iHS does not readily detect $H B B$ or G6PD (Voight et al. 2006), and related

192 statistics target other evolutionary scenarios like soft sweeps or sweeps near completion

193 (Garud et al. 2015; Sabeti et al. 2007). The statistic $n S_{\mathrm{L}}$ does implicate $H B B$ (Ferrer-Admetlla

194 et al. 2014; Laval et al. 2019), but this statistic, like any based on haplotype homozygosity,

195 is sensitive to relatedness among samples and new mutations or sequencing errors that

196 disrupt the otherwise perfect similarity among haplotypes. However, the signal of a sweep

197 may extend beyond the range of haplotype homozygosity, in the form of reduced, but

198 not necessarily nonzero, nucleotide diversity linked to the swept haplotype. In other

199 words, individuals homozygous for a swept allele have fewer total heterozygous sites than

200 individuals homozygous for the ancestral allele.

201 The second evolutionary step, which distinguishes an Arrested Sweep from an

202 ongoing partial sweep, is balancing selection maintaining the polymorphism at the

203 optimal frequency in the ingroup while purifying selection excludes it from the outgroup.

204 Assessing this signal starts with Fst within the ingroup. An arrested sweep maintained at

205 constant frequency by balancing selection will show low FST among populations that are

206 experiencing the same selection pressure. An ongoing sweep should not show this pattern

207 and may even show unusually high Fst $_{\text {if }}$ the sweep has proceeded farther in some 
208 populations than others. In addition, purifying selection acts in the outgroup where there

209 is no heterozygote advantage, so the MAF in the outgroup should be very close to zero.

210 Our final test statistic II (equation 7) is a product of metrics that capture these

211 steps: positive sweep in the target population, balancing selection across the ingroup, and

212 purifying selection in the outgroup. There is no upper limit to II and unusual values of II

213 are defined in comparison to the genome-wide average.

215 Results

216

217 in simulations

218 Simulation results show that ia values are typically higher for balanced

219 polymorphisms, relative to neutral polymorphisms, under a wide range of parameters

220 (Supp Figure 1). Intermediate $g$ values (500 to $1000 \mathrm{bp}$ ) were optimal to minimize the

221 overlap between selection and neutral windows. The power of $\mathrm{a} a$ is maximized when

222 recombination rates are low, the polymorphism is old, and mutation rates surrounding

223 balanced polymorphisms are similar to those in neutral regions. Skewing the expected

224 MAF had little effect, in contrast to many common tests for balancing selection that seek

225 intermediate-frequency variants. For $g$ of 500 and human-relevant parameters, variants

226 with approximately $a \geq 10$ should be enriched for true balanced polymorphisms, though

227 with inevitable false positives and false negatives. 
229 in human population data

230 In our focal population YRI (Yoruba in Ibadan, Nigeria), ' $a$ with $g$ of 500 ranged

231 from 0 to 59.8 (median $=0.2,95 \%$ interval $=0.0$ to 5.9 ; Figure $2 \mathrm{~A}$ ). Only $0.56 \%$ of variants

232 had $\& \geq 10$. Variants in or near the HLA accounted for $15 \%$ of variants with $\& \geq 10$, a

233 majority $(66 \%)$ of variants in the top $0.05 \%(\% \geq 22.6)$ and the 58 highest variants (Figure

234 2B). There are 243 coding genes with at least one exonic $\&$ value $\geq 10$, including $A B O$

235 (Figure 2C). The glycophorins do not show a strong exonic signal but many high-

236 variants, including two reaching the top $0.05 \%$ threshold, occur in the intergenic region

237 between GYPE and FREM3 where the strongest signal of selection and disease-association

238 of the glycophorin cluster has previously been detected (Leffler et al. 2013; Malaria

239 Genomic Epidemiology Network 2015; Figure 2D). These results suggest that "a does

240 capture the intended empirical selection signal. The top 50 genes outside of the HLA

241 region (Table 2; Supp Table 1; Figure 2 E,F), based on \&a in exons or within $1 \mathrm{~kb}$ upstream,

242 all showed \& $>15.5$ (top $0.15 \%$ of variants). 

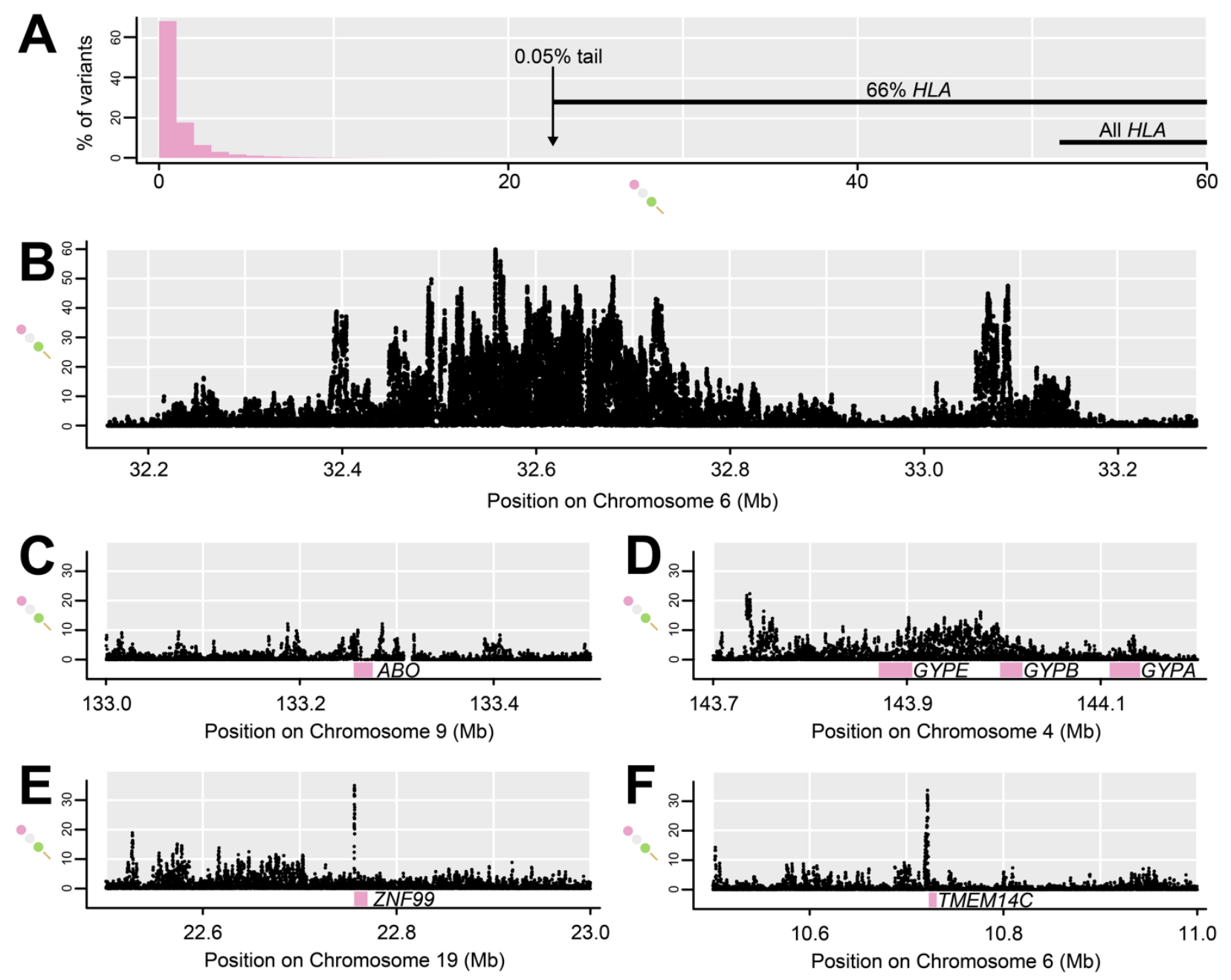

244 Figure 2. Distribution of $\&$, including notable genomic outliers. (A) Histogram of $\&$ shows that the vast 245 majority of variants have low values, and the $0.05 \%$ which exceed 22.6 are enriched for variants in or near 246 the HLA. (B) This section of the HLA region shows the highest "a values in the genome. (C) $A B O$ slightly 247 surpasses $\$ \mathrm{a}$ of 10 within the coding region. (D) Noncoding regions near glycophorin genes show high "a. 248 (E) The highest \& in or near a gene occurs just upstream of ZNF99 (Table 2). (F) One of the highest $\%$ sites 249 in or near a gene occurs just upstream of TMEM14C (Table 2). 
253 uniform distribution of expected p-values (Supp Figure 2). The fit is poor for higher values

254 of $\Psi$, but since the practical question is whether low $\Psi$ values are lower than would be

255 expected by chance, this is unimportant. Upon adding a single window showing parallel

256 adaptation to this set of 10,000 , the adaptive window typically shows the lowest $\Psi$. With

257 a selection coefficient of 0.05 , most (65\%) adaptive windows have lower $\Psi$ than all neutral

258 windows, and $45 \%$ are individually significant ( $\Psi<0.05 / 10,001$ ), even though only $4 \%$

259 show $F_{S T}$ higher than all neutral $F_{S T}$ values for all three pairwise comparisons. Therefore,

260 combining FST $_{\text {ST }}$ values into $\Psi$ provides higher power to detect adaptation than individual

261 pairwise $\mathrm{F}_{\mathrm{ST}}$. With a stronger selection coefficient of 0.5 , either $\Psi$ or $\mathrm{F}_{\mathrm{ST}}$ alone perfectly

262 distinguishes selection from neutrality.

263

$264 \Psi$ in human population data

265 In populations from Africa, Europe, and Asia, $\Psi$ with $g$ of $5 \mathrm{~kb}$ could be estimated

266 for over 520,000 windows, representing over $2.6 \mathrm{~Gb}$. The distribution of $\Psi$ closely

267 approximated a uniform neutral distribution of $p$-values, with $7 \%$ of windows showing $\Psi$

268 less than 0.05 . The median number of common variants (MAF $\geq 5 \%$ ) in these low- $\Psi$

269 windows was 16, similar to the genome-wide median of 14 . Only a single window,

270 overlapping the majority of the coding sequence of gene PTK6, had an individually

271 significant $\Psi$ (less than corrected $\alpha$ of 1e-07; Figure 3A). However, windows with low $\Psi$ 
272 are good candidates for repeated shifts, even if not individually significant. Windows

273 overlapping $A C K R 1$ occurred in the $0.03 \%$ most extreme windows $(\Psi=0.0004$ ), while

274 windows overlapping $C R 1$ occurred in the $0.5 \%$ most extreme windows ( $\Psi=0.0057$ ).

275 Low- $\Psi$ outliers are enriched for genic and exonic windows (Figure 3B), consistent with $\Psi$

276 capturing adaptive variation. After staggering window starting positions to capture all

277 outliers, the top 50 genes have an exon overlapping at least one window with $\Psi$ under

2780.0002 (Supp Table 2). Results were largely similar with $g$ of $50 \mathrm{~kb}$ (Figure 3C,D), indicating

279 that $\Psi$ is robust to the choice of window size. Because these wider windows often overlap

280 more than one gene, complicating interpretation, we focus on results with $g$ of $5 \mathrm{~kb}$ (Table

$2812)$.

282 

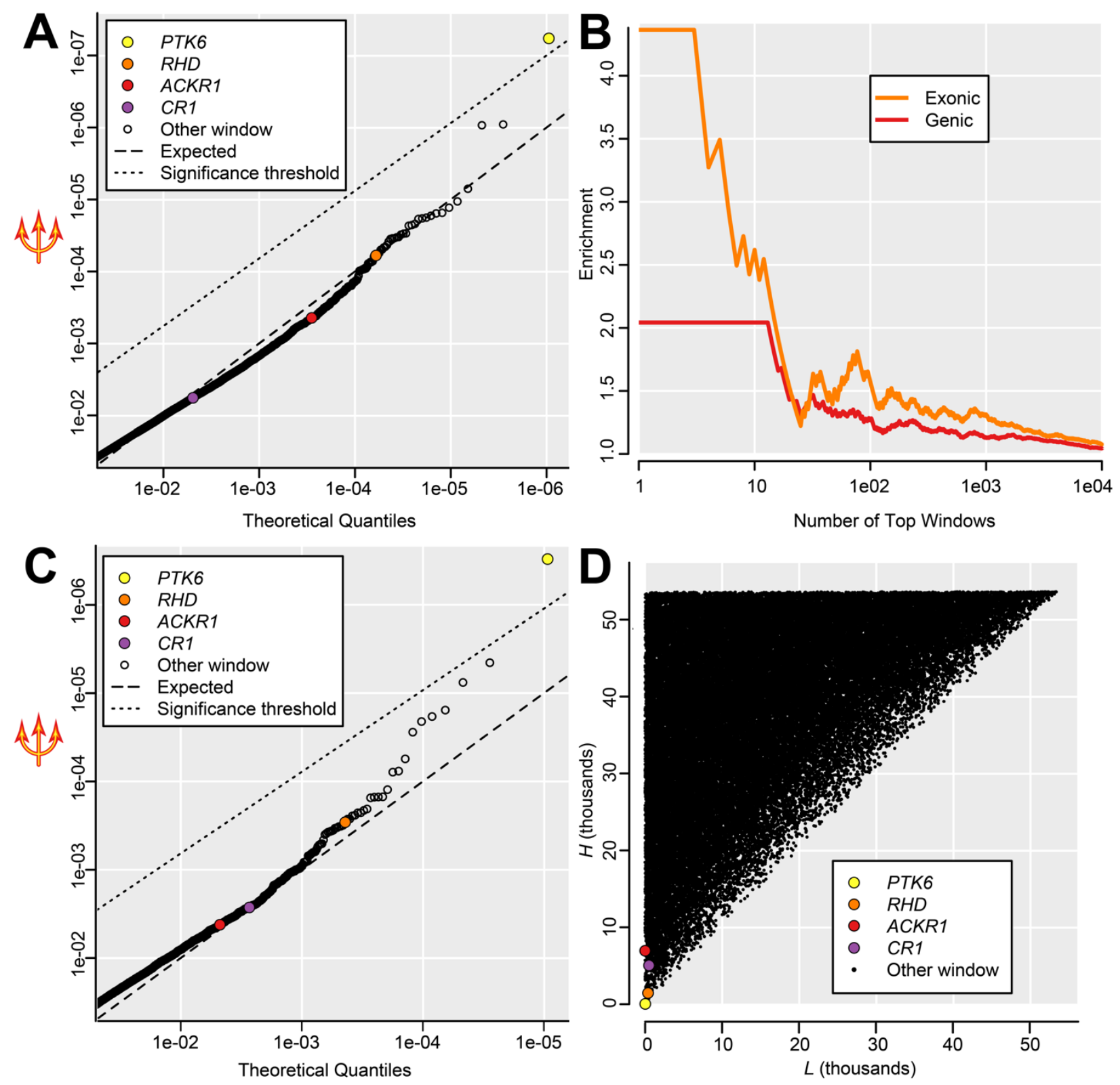

284 Figure 3. Genomic outliers for $\Psi$. (A) Partial QQ plot showing $\Psi$ less than 0.05 , representing $7 \%$ of genomic

285 windows, for $g=5 \mathrm{~kb}$. A single window overlapping PTK6 surpasses the significance threshold, while most

286 other windows are close to the expected neutral distribution. Although windows overlapping $A C K R 1, C R 1$,

287 and $R H D$ are not individually significant, they occur among the $0.5 \%$ most extreme windows. (B) $5 \mathrm{~kb}$

288 windows with low $\Psi$, shown for continuously increasing thresholds, are enriched for windows that overlap

289 genes, and even more so for windows that overlap exons, consistent with $\Psi$ capturing phenotypically

290 relevant polymorphism. (C) Partial QQ plot showing $\Psi$ less than 0.05 , representing $8 \%$ of genomic windows, 
291 for $g=50 \mathrm{~kb}$. As in (A), a window overlapping PTK6 is individually significant while $A C K R 1, C R 1$, and $R H D$

292 are among the top outliers. (D) Lowest rank $L$ (most extreme $\mathrm{F}_{\mathrm{ST}}$ ) and highest rank $H$ (least extreme $\mathrm{F}_{\mathrm{ST}}$ ) for $293 g=50 \mathrm{~kb}$, highlighting genes in outlier windows.

\section{II in simulations}

In simulations, II is substantially higher under an Arrested Sweep than under

297 neutrality (Supp Figure 3). Under strong selection (heterozygote fitness = 1.99), almost all

298 simulations produced higher II (median = 150; 95\% interval $=64$ to 237 ) than neutral

299 simulations (median $=1 ; 95 \%$ interval $=0.01$ to 32 ). Under weak selection (heterozygote

300 fitness $=1.09$ ), II still typically exceeded the neutral distribution (median $=43 ; 95 \%$

301 interval $=17$ to 78 ). II is calculated from several unrelated metrics, and each component

302 has a distribution under selection that differs from the neutral distribution, resulting in a

303 statistic that is very sensitive to Arrested Sweeps. In practice, these results suggest that

304 under similar parameters, variants with II $\geq 20$ should be enriched for true balanced

305 polymorphisms, while variants with II $\geq 100$ are very unlikely to be neutral.

II in human population data

Within our focal population YRI, using all five sub-Saharan African populations to

309 calculate $F_{S T}$ and $p$, and Europe as the outgroup, II ranged from 0 to 511.2 (median = 1.0,

$31095 \%$ interval $=0.0$ to 23.8 ; Figure $4 \mathrm{~A})$. The HLA region accounted for $4 \%$ of autosomal

311 variants in the top $0.05 \%$, with additional outliers closely linked to it including the top 
312 autosomal variant in an intron of $B A K 1$ (Figure 4B), but this HLA enrichment was much

313 less pronounced for II than it was for \&. Our target genes $H B B$ and G6PD, and specifically

314 their phenotype-associated nonsynonymous polymorphisms, showed very high II and

315 are among the most extreme outliers. In $H B B$, the Glu-Val missense variant rs334 that

316 causes sickle-cell anemia shows II of 194.8, placing it in the top $0.005 \%$ of all variants

317 (Figure 4C). Only 144 variants in the entire genome have a higher II than rs334. If variants

318 on chromosomes 6 (HLA) and X (see below) are ignored, rs334 remains among the top

31914 variants, and the only one within a protein-coding gene. In G6PD, the Asn-Asp

320 missense variant rs1050829 associated with G6PD deficiency shows II of 68.8, placing it

321 in the top $0.5 \%$ of all variants, both on the $\mathrm{X}$ chromosome and genome-wide (Figure 4D).

322 The top 50 genes outside of the HLA region (Supp Table 3; Figure $4 C, E, F$ ), based on II in

323 exons or within $1 \mathrm{~kb}$ upstream, all exceed II of 99.5 (top $0.025 \%$ of variants). This list

324 includes several genes on chromosome 6 that could reflect the effect of HLA selection, as

325 its signal appears to extend for several megabases surrounding the HLA (Figure 4B). While

$326 H B B$ is the highest autosomal gene, it is exceeded more than 2.5 -fold by two adjacent X-

327 linked genes, $A B C B 7$ and $R L I M$ (Figure 4E). The $A B C B 7$ signal includes Ala-Val missense

328 variant rs1340989 (II = 272.9) and intron variant rs372972791 with the highest observed

329 II of 511.2. $A B C B 7$ is the peak of a $3 \mathrm{Mb}$ region from $\mathrm{X}$ positions 74.5 to $77.5 \mathrm{Mb}$, with

330 more than 100 variants showing II over 200, a threshold that excludes all other X-linked

331 variants and all but 17 autosomal variants. 

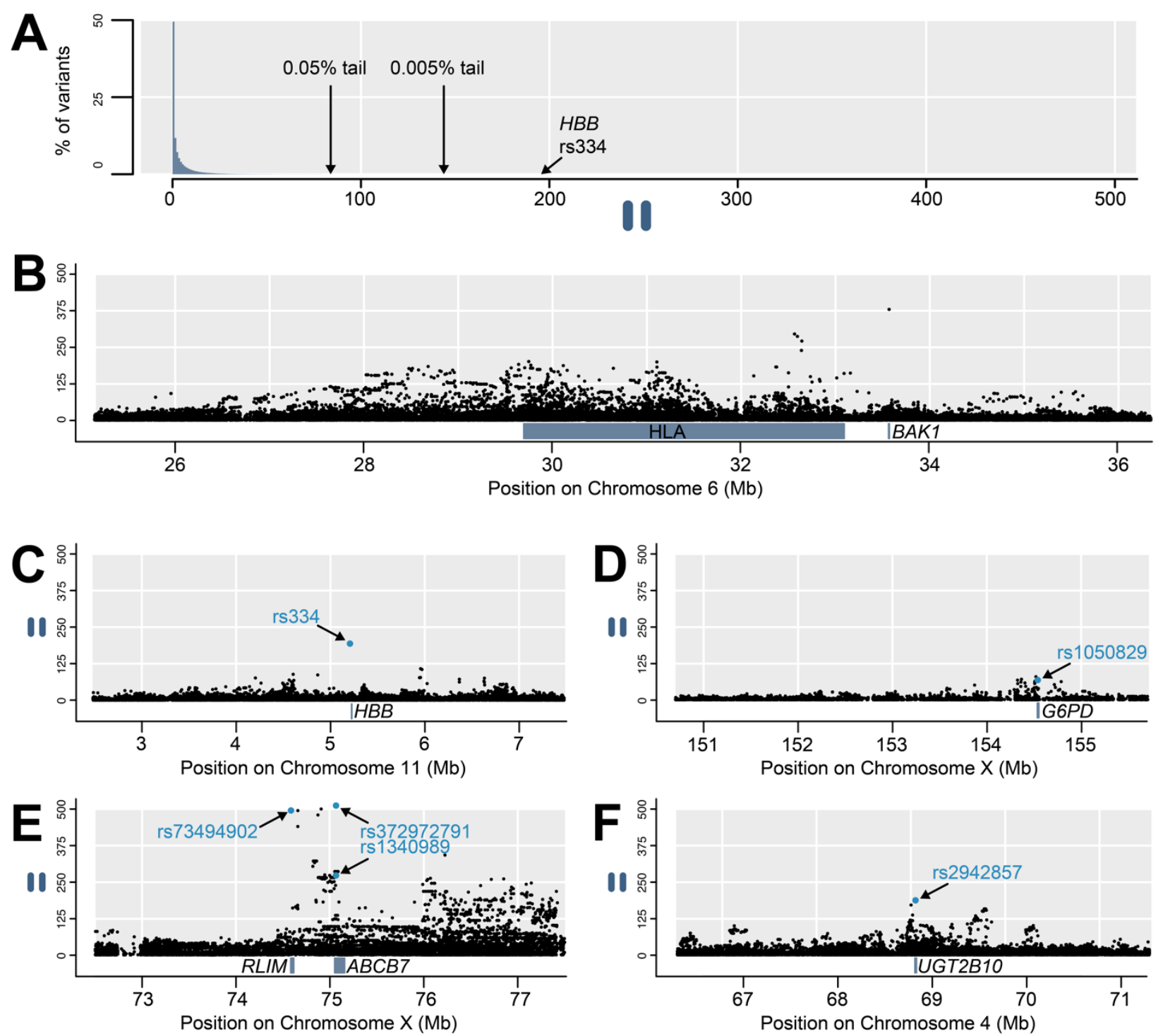

334 Figure 4. Distribution of II, including notable genomic outliers. (A) Histogram of II shows that the vast

335 majority of variants have low values, though the sickle-cell polymorphism rs334 occurs in the $0.005 \%$ tail.

336 (B) High II occurs throughout the HLA region and this signal extends beyond its borders, including in BAK1.

337 (C) Sickle-cell polymorphism rs334 in HBB shows exceptionally high II. (D) Several variants in or near G6PD

338 show high II, including disease-linked missense variant rs1050829. (E) The highest II values in the genome

339 by far occur in this section of the $\mathrm{X}$ chromosome, with the highest variants in RLIM and $A B C B 7$. (F) Splice-

340 acceptor variant rs2942857 in UGT2B10 is the highest exonic autosomal variant after rs334. 
343 Table 2. Top five genes for each statistic when occurring in exons or within $1 \mathrm{~kb}$ upstream,

344 excluding the HLA region.

\begin{tabular}{|c|c|c|c|c|}
\hline Gene & Chromosome & Statistic & Value & Description \\
\hline ZNF99 & 19 & ia & 34.97 & $\begin{array}{l}\text { zinc finger protein, possible role in } \\
\text { viral infection }\end{array}$ \\
\hline$S N \times 29$ & 16 & ia & 34.92 & $\begin{array}{l}\text { sorting nexin, may regulate } \\
\text { intracellular trafficking }\end{array}$ \\
\hline$C Y P 2 B 6^{a}$ & 19 & 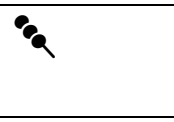 & 32.56 & $\begin{array}{l}\text { cytochrome P450 family enzyme, } \\
\text { role in metabolizing xenobiotics }\end{array}$ \\
\hline TMEM14C & 6 & 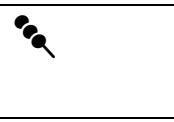 & 28.77 & $\begin{array}{l}\text { heme precursor transporter, role in } \\
\text { erythropoiesis }\end{array}$ \\
\hline KRTAP9-8 & 17 & 8 & 28.47 & $\begin{array}{l}\text { keratin associated protein with role } \\
\text { in hair structure }\end{array}$ \\
\hline PTK6 & 20 & $\Psi$ & $1.54 \mathrm{e}-08$ & $\begin{array}{l}\text { cytoplasmic nonreceptor protein } \\
\text { kinase, epithelial signaling role }\end{array}$ \\
\hline SRMS & 20 & $\Psi$ & $3.42 \mathrm{e}-07$ & tandem paralog of $P T K 6$ \\
\hline FBXO31 & 16 & $\Psi$ & $8.85 e-07$ & F-box protein with regulatory role \\
\hline$S P N S 2^{a b}$ & 17 & $\Psi$ & $9.10 e-07$ & $\begin{array}{l}\text { transporter of sphingosine 1- } \\
\text { phosphate }\end{array}$ \\
\hline TTLL10 & $1^{c}$ & $\Psi$ & $1.03 e-06$ & polyglycylase \\
\hline$R L I M$ & $x$ & II & 495.12 & $\begin{array}{l}\text { zinc finger protein transcription } \\
\text { regulator }\end{array}$ \\
\hline$A B C B 7^{\circ}$ & $X^{c}$ & II & 272.91 & $\begin{array}{l}\text { heme transporter, role in } \\
\text { erythropoiesis }\end{array}$ \\
\hline$H B B^{a b}$ & 11 & II & 194.83 & $\begin{array}{l}\text { oxygen-transport metalloprotein in } \\
\text { erythrocytes }\end{array}$ \\
\hline UGT2B 10 & 4 & II & 187.49 & $\begin{array}{l}\text { liver glycosyltransferase, role in } \\
\text { metabolizing xenobiotics }\end{array}$ \\
\hline$R A B G A P 1 L^{a}$ & $1^{c}$ & II & 162.56 & $\begin{array}{l}\text { GTPase-activating protein, } \\
\text { regulatory role in hematopoiesis }\end{array}$ \\
\hline
\end{tabular}

a associated with erythrocytes or erythroid cells (text mining score $>0.25$ ) 
low-recombination region

Among the top 50 outliers for each test, there is significant enrichment for the "antigen binding" molecular function GO term ( 9 genes, of which 8 are "a outliers, FDR = 0.049), and the "endocytosis" biological process GO term (16 genes, FDR $=0.038$ ). We specifically tested for genes important to red blood cells, given their centrality to our exemplar genes and to Plasmodium invasion, and we observe substantial enrichment.

5B). Enrichment is even greater among genes with higher text mining scores, for which

363 this analysis, our top hits are significantly enriched for correlations with malaria

364 susceptibility in genome-wide association studies ("GWAS"; 2.9 -fold enrichment; 9 of 150

365 genes; $p<0.01$; Supp Tables 1, 2, and 3). These nine GWAS hits include known exemplar

366 gene $H B B$ and adjacent gene pair METTL7B and ITGA7 that share a signal with each other,

367 but even if $H B B$ is discarded and the adjacent pair is merged, the enrichment is still 
368 significant for seven matches $(p<0.05)$. We do not see an enrichment for proteins

369 previously shown to interact with Plasmodium or piroplasmid parasites $(p>0.05)$. Many

370 genes are observed both among our outliers and among those of nine previous genome-

371 wide scans for selection using various tests (Supp Table 4). There is a trend toward

372 enrichment with all nine previous scans, though it's not always significant. Notable

373 comparisons include five genes identified by both \& and a composite likelihood scan for

374 balancing selection (DeGiorgio et al. 2014; 13.4-fold enrichment, $p<1$-04), thirteen

375 genes identified by both $\Psi$ and the parallel adaptive divergence scan at the level of

376 individual variants (Tennessen and Akey 2011; 4.1-fold enrichment; $p<1 e-05$ ), and two

377 genes identified by both II and iHS (Voight et al. 2006; 2.9-fold enrichment; $p$ > 0.05).

378 Finally, across all tests we see an enrichment for low-recombination regions of the

379 genome (2.5-fold enrichment; 20 of 150 genes; $p=0.0001)$, especially for II which

380 encompasses long-range LD (Table 2; Supp Tables 1, 2, and 3). We did not exclude these

381 low-recombination genes, because we suspect they are not false positives but rather

382 reflect enhanced power to detect selection in these regions, and because our II exemplar

383 gene G6PD occurs in a low-recombination region. 

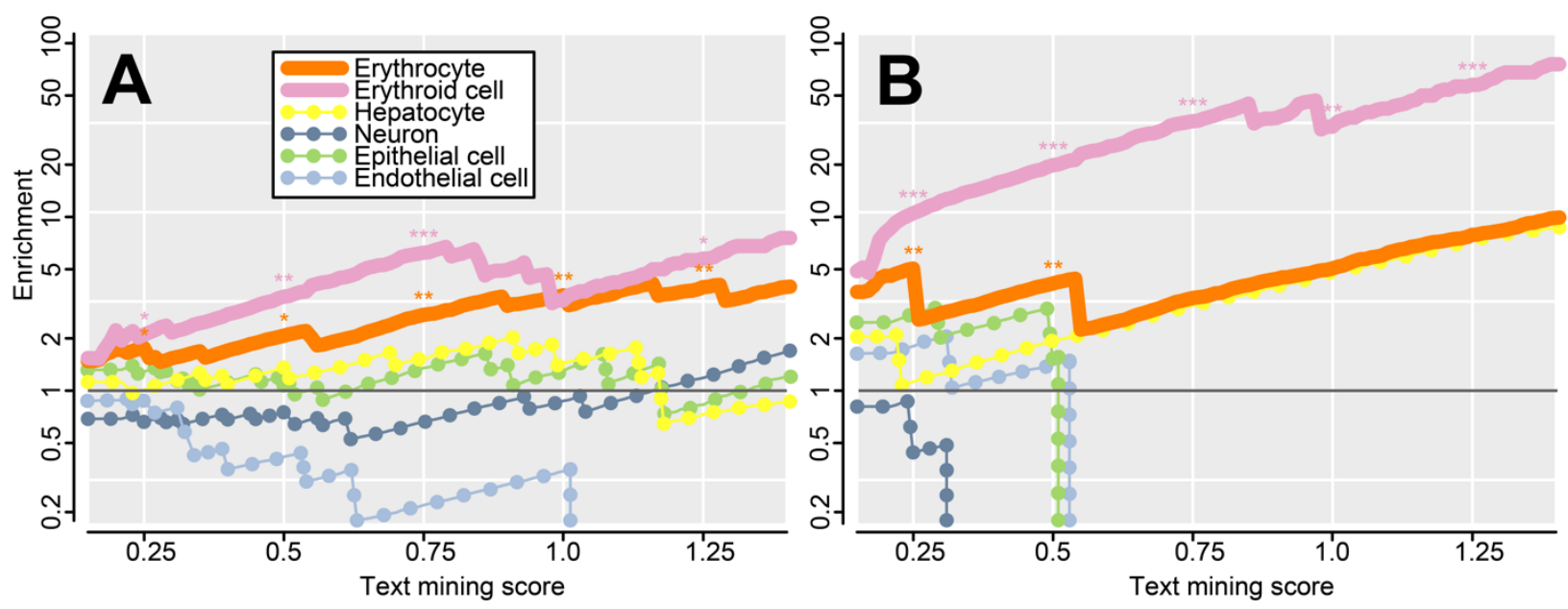

Figure 5. Enrichment for genes associated with various cell types, with higher scores indicating a stronger association via text mining (Santos et al. 2015; Rouillard et al. 2016). At intervals of 0.25, significant enrichments are indicated $\left({ }^{*} \mathrm{p}<0.05 ;{ }^{* *} \mathrm{p}<0.01 ;{ }^{* * *} \mathrm{p}<0.001\right)$. Genes associated with erythrocytes and erythroid cells are significantly enriched (solid lines), and enrichment increases with score, suggesting a prevalence of genes with particularly high specificity to red blood cells. Enrichment is higher among erythroid cell genes than among erythrocyte genes, suggesting that many outliers are more important in erythroid progenitors than in mature cells. No significant enrichment is observed in control tissues (dotted

392 lines). (A) The top 150 genes for the three tests (Supp Tables 1, 2, and 3). (B) The top fifteen genes for the 393 three tests (Table 2).

\section{Discussion}

Three new statistical assays for non-neutral polymorphism 
401 human genome (Sabeti et al. 2007; Akey 2009; Fan et al. 2016). However, despite this

402 plethora of statistical tools, it remains challenging to conclusively identify instances of

403 positive or balancing selection in humans. Genes which are known to behave non-

404 neutrally, either because fitness or phenotypic impact of genotypes have been measured

405 directly (e.g. overdominance at $H B B$; Aidoo et al. 2002), or because of evidence from other

406 species (e.g. trans-species polymorphisms at $A B O$ and $G Y P A / B / E$; Ségurel et al. 2012;

407 Leffler et al. 2013), are not necessarily outliers in scans for selection across human

408 populations. In the approach presented here, we focused on genes with polymorphisms

409 already known to be adaptive and shaped by infectious disease, and we attempted to

410 capture unusual empirical patterns at these genes that are plausibly driven by selection

411 in accordance with population genetic theory. Our statistics are inspired by patterns at

412 malaria-relevant genes in humans and they reveal numerous outliers with potential

413 relevance to malaria. This is because malaria has been such a strong selective pressure on

414 our species, and because our adaptive response to Plasmodium frequently leads to these

415 population genetic patterns, making them likely indicators of malaria resistance loci.

416 However, malaria is not the only selective pressure capable of producing these patterns,

417 and these tests are potentially applicable to detecting selection due to other causes

418 and/or in other species.

419 Both simulated and empirical results suggest that these tests are robust. However,

420 they carry several caveats and limitations. Like other outlier-based tests (Akey 2009), these 
421 tests are intended to identify genomic regions that are most suggestive of certain

422 hypothesized modes of selection, under the a priori assumption that a small proportion

423 of the genome did evolve according these modes. They are not intended to test a null

424 hypothesis of complete neutrality, and there are no clearly defined thresholds beyond

425 which neutrality can be rejected. None of the tests employ outgroup species and so are

426 naïve with respect to derived or ancestral status of alleles, but if selective pressures

427 fluctuate and act on standing variation then even an ancestral allele could be adaptive. As

428 with most selection scans, these tests assume that mutation and recombination rates

429 across the genome are similar; as this assumption is typically violated, their power may

430 vary across genomic regions. Each test also carries its own specific caveats. For Divergent

431 Haplotypes, selectively neutral processes like gene conversion or introgression (e.g. from

432 archaic hominids; Ragsdale and Gravel 2019) could lead to high sequence divergence

433 between haplotypes and thus elevated ' $a$, as could mis-aligned reads from paralogs.

434 Furthermore, the most polymorphic genomic regions can be poorly represented in

435 population genomic datasets if high sequence divergence and large indels impede

436 genotyping, so some of the strongest Divergent Haplotypes signatures could be missed

437 by \& in practice. For Repeated Shifts, $\Psi$ approximates a p-value but is not formally a p-

438 value for a defined null hypothesis. FST depends on the MAF, and single-variant-based

439 tests for parallel Fst require considerable filtering based on allele frequency (Tennessen

440 and Akey 2011). However, since $\Psi$ considers FST across numerous variants within a 
441 window, typically showing a wide range of MAFs, it should be largely robust to this effect.

442 For Arrested Sweeps, II carries the assumption that differences in heterozygosity are

443 caused by a shared physical and evolutionary association with the target locus. This

444 assumption is violated if there is LD not caused by physical linkage (i.e. due to family or

445 population structure), or if LD due to sampling error is substantial enough to affect the

446 true LD signal. The latter can occur when regions of extraordinarily high polymorphism or

447 haplotype structure such as a centromere or the HLA (Figure 4B) are included in the

448 window used to estimate heterozygosity. II depends on selection acting consistently one

449 way in the ingroup and another way in the outgroup, which may not always be the case.

450 All of these statistics can best be thought of as tools for identifying candidate genes, but

451 follow-up study is required before drawing firm conclusions about evolutionary history or

452 functional impact.

453 The tests detect the six exemplar loci which motivated this study, but with varying

454 degrees of success. Most strikingly, II is a near-perfect test for an $H B B$-like signal, as $H B B$

455 is the third most extreme gene and the top autosomal gene. ACKR1 and G6PD are also

456 notable outliers, falling in the top $1 \%$ of genes for their respective statistics. The remaining

457 three exemplar loci are less extreme outliers, but all fall within the top $5 \%$ of genes for

458 their respective statistics. As noted above, \& may be underpowered if some

459 polymorphisms are absent from the dataset, as is the case for $A B O$ and $G Y P A / B / E$, which

460 could partially explain why this statistic was the least powerful at detecting its exemplar 
461 loci. Other loci are also strongly associated with malaria but would have made poor

462 exemplar genes in this analysis and were therefore ignored. For example, Plasmodium has

463 driven an Arrested Sweep on SLC4A1 in Southeast Asia (Paquette et al. 2015), but these

464 populations are poorly represented in the 1000 Genomes. Also, though ATP2B4 is globally

465 associated with malaria (Malaria Genomic Epidemiology Network 2019), evidence for non-

466 neutral evolution is mild and/or very geographically localized (Gelabert et al. 2017;

467 Gouveia et al. 2019). Indeed, $A T P 2 B 4$ was not a notable outlier in any test ( $\bullet=5.98, \Psi=$ 468 0.0094, II = 6.94).

$470 \quad$ Hallmarks of adaptation to malaria

472 of hominid primates and other vertebrates, yielding the three hallmarks of selection

473 presented here (Table 1). Each hallmark has occurred on a different timescale and is

474 associated with distinct parasite pressures. First, genetic variants which conveyed

475 resistance to ancient Plasmodium parasites in our pre-human ancestors, if not fixed long

476 ago, persist as balanced polymorphisms with a Divergent Haplotypes signature. These

477 variants, at loci like $A B O, G Y P A / B / E$, and the HLA, have also been shaped by other

478 pathogens over millions of years. The importance of Plasmodium itself as a driver of

479 diversity is unknown but highly plausible given the connection between these loci and

480 malaria resistance (Ségurel et al. 2013). Second, the Repeated Shifts pattern is tied to the 
483 originated first, over 20,000 years ago, while $P$. falciparum only arose within the past

484 10,000 years (Loy et al. 2017; Daron et al. 2020). The dramatic selective sweep of the Duffy-

485 null allele in Africa conveyed resistance to $P$. vivax and could have eliminated it as a human

486 parasite, but a lineage of $P$. vivax survived in Asia where it persists widely to this day

487 (Hamblin and Di Rienzo 2000; Loy et al. 2017). It is unclear why Duffy-null did not also

488 spread widely beyond Africa, but instead P. vivax in Asia selected for a different $A C K R 1$

489 allele, Fy ${ }^{a}$ (King et al. 2011; Chittoria et al. 2012). CR1 shows a similar signature of parallel

490 evolution and impacts resistance to both $P$. vivax (Prajapati et al. 2019) and P. falciparum

491 (Tham et al. 2010), suggesting that either or both of these species may have driven its

492 evolution. Third, Arrested Sweeps are the most recent evolutionary scenario and are

493 associated with the expansion of $P$. falciparum, which likely dispersed across sub-Saharan

494 Africa along with agriculture, which facilitates optimal mosquito habitat, during the past

495 few thousand years. Resistance alleles at $H B B$ and G6PD spread among the same locations

496 on a similar timescale (Tishkoff et al. 2001; Shriner and Rotimi 2018; Laval et al. 2019). Each

497 hallmark of selection might only be detectable within its particular timescale. For example,

498 an Arrested Sweep polymorphism maintained by a deleterious homozygote genotype is

499 inherently unstable and poised to be replaced by an allele that conveys the heterozygote

500 advantage without the costs, as has already begun for $H B B$ (Modiano et al. 2001). Thus, 
501 any hypothetical Arrested Sweep caused by $P$. vivax prior to the Duffy-null sweep could

502 have been subsequently lost.

503

We observed an enrichment for malaria-associated chromosomal regions from

504 three large GWAS (Timmann et al. 2012; Malaria Genomic Epidemiology Network 2019;

505 Milet et al. 2019), especially among $\Psi$ outliers (Supp Table 2). Two particularly promising

506 candidates are PTPRM and MYLK4, which are among the very strongest candidates for

507 recurrence of mild malaria attacks in infants (Milet et al. 2019). In particular, PTPRM was

508 the top prioritized gene in the GWAS based on functional consequences $(p=3.8 \mathrm{e}-08$;

509 Milet et al. 2019), and the top disease-associated variant in the gene occurs in between

510 the two variants that define the Repeated Shifts signal ( $\Psi=2 e-04$ ), just upstream of an

511 alternate transcript start. Furthermore, less than $2 \mathrm{~kb}$ upstream of malaria-associated

512 SPNS2, the fourth-highest $\Psi$ outlier (Table 2), there are three variants within 36 bp of

513 each other that have undergone three distinct allele frequency shifts in Africa, Asia, and

514 Europe. Finally, adjacent genes METTL 7B and ITGA7 share a Repeated Shifts signal and a

515 GWAS signal and are both overexpressed during severe malaria (Lee et al. 2018). Any gene

516 at the intersect of selection signal and phenotype association is worthy of further

517 consideration, as such combined evidence has been instrumental in implicating known

518 loci like GYPA/B/E (Malaria Genomic Epidemiology Network 2015). 
522 genes with a role in red blood cells (Figure 5). The most severe pathology impacting

523 human fitness occurs during the blood stage of the Plasmodium life cycle, and our

524 exemplar genes on which we based our tests all act during this stage. There are two

525 principal mechanisms by which such genes may impact blood-borne parasites. In the first

526 mechanism, erythrocyte surface proteins encoded by transmembrane genes like $A C K R 1$,

$527 C R 1, A B O, G Y P A$, and GYPB act as receptors for Plasmodium ligands to facilitate invasion

528 (Cowman et al. 2017) or mediate cytoadherence (Cserti and Dzik 2007). Several such

529 receptors remain to be discovered (Cowman et al. 2017), but there are few compelling

530 candidates among our novel outliers. The strongest contender is $R H D(\Psi=6 \mathrm{e}-05$; Figure

5313 ), which encodes the transmembrane D antigen for the Rh blood group, a component of

532 the erythrocyte cell surface connected to Plasmodium invasion (Chung et al 2008).

533 Remarkably, RHD also shows a moderate Divergent Haplotypes signature within its

534 coding region ( $\mathrm{a}=13.2$, higher than either of the Divergent Haplotypes exemplar genes),

535 suggesting it could have been subject to both adaptive processes. While the signal of

536 selection on $R H D$ is convincing, unlike $A C K R 1$ and $C R 1$ this signal involves Europe-specific

537 divergence and thus shows a slightly different evolutionary history, perhaps driven by

538 other parasites (Novotná et al. 2008). Many other outliers also encode transmembrane

539 proteins, but there is little evidence that they are expressed on the surface of mature

540 erythrocytes. 
542 and cellular integrity. Such changes can affect intracellular parasite growth and survival,

543 though perhaps with reduced function or a similar cost to the host. Hemoglobinopathies

544 and enzymopathies that protect against malaria are conveyed by $H B B, G 6 P D$, and other

545 loci like FECH (Taylor et al. 2013; Smith et al. 2015). Across all three tests, several of our

546 top outlier loci play keys roles in erythropoiesis (Table 2; Supp Tables 1, 2, and 3), and

547 thus we observe more evidence for adaptation via this mechanism than via the first

548 mechanism of invasion receptors. Loci involved in erythroid development are not

549 necessarily expressed in the mature proteome (Bryk and Wiśniewski 2017), and thus we

550 see greater enrichment for (precursor) erythroid cell genes than for (mature) erythrocyte

551 genes (Figure 5). In addition to $H B B$, our most extreme outliers include TMEM14C and

$552 A B C B 7$, both implicated in erythroid maturation (Conte et al. 2015; Table 2). TMEM14C

553 encodes a transmembrane protein essential for erythroid synthesis of heme (Yien et al.

554 2014), and many of the highest \& variants occur in a $4.5 \mathrm{~kb}$ region in its upstream cis-

555 regulatory region ( ${ }^{\circ}=28.8$, Figure $2 F$ ). As further evidence for malaria-relevant selection

556 independent of the ia signal, variants near TMEM14C are also among the most

557 differentiated between Europeans and Africans genome-wide ( $\left.F_{S T}>0.8\right)$ and may underlie

558 the pronounced differences in TMEM14C expression between these continents (Quach et

559 al. 2016). $A B C B 7$, a transmembrane iron transporter in the heme pathway, is essential for

560 erythropoiesis and causes anemia when deficient ( II = 272.9; Pondarre et al. 2007; 
Severance and Hamza 2009; Figure 4E). The outlier region centered on $A B C B 7 / R L / M$ far is part of a glycosyltransferase family that catalyzes heme breakdown (Sticova and Jirsa 2013; Figure 4F). Other outliers have roles in hematopoiesis (RABGAP1L, Roberti et al. 2009; MAP1LC3B, Kang et al. 2012) or erythrocyte morphology (MYH9, Smith et al. 2019).

Adaptation to infectious disease beyond malaria and the red cell

573 diet, environmental toxins, and other infectious diseases (Fan et al. 2016). Consistent with

574 these expectations, many of the outliers in our tests have no obvious connection to particular previous scan for selection, though there is enrichment for repeat outliers (Supp

577 Table 4), including LGALS8 (Andrés et al. 2009; DeGiorgio et al. 2014; Bitarello et al. 2018),

578 FBXO31 (Leffler et al. 2013), SORD (Tennessen and Akey 2011; DeGiorgio et al. 2014), and

579 DMBT1 (Leffler et al. 2013; DeGiorgio et al. 2014; Siewert and Voight 2017). One of the

580 clearest signals of selection is on PTK6 (Figure 3), a tyrosine-protein kinase involved in 
581 several cancer pathways. PTK6also shows parallel evolution at the variant level (Tennessen

582 and Akey 2011) and is speculated to harbor adaptive polymorphisms impacting gastric

583 bacterial infection (Jha et al. 2015). However, the specific selective pressure on PTK6, and

584 most other outliers, is unknown.

Our outliers include numerous immune-related genes, which are especially prone to positive and balancing selection (Barreiro and Quintana-Murci 2010; Spurgin and Richardson 2010). This trend does not preclude a role for Plasmodium, but it is also consistent with selection via other infectious agents from viruses to macroparasites. Many and II, but we have largely ignored these, as balancing selection on the HLA is already well documented (Spurgin and Richardson

591 2010). Excluding them, the "a outliers are enriched for "positive regulation of immune response" and "antigen-binding", a trend largely driven by immunoglobulin genes (Supp

593 Table 1). Cumulatively across all three tests there is enrichment for "antigen-binding" and

594 "endocytosis" which also encompasses the immunoglobulin genes as well as other

595 immune-relevant genes like dendritic cell receptor CD209, T-cell surface glycoprotein

596 CD5, and macrophage-expressed CLEC4F. Many of the immunity-related outliers encode

597 transmembrane proteins, especially outliers for \& and by a lesser extent $\Psi$. This pattern

598 is consistent with selection for novelty in parasite-recognition proteins, leading to stable

599 negative frequency-dependent selection (Divergent Haplotypes) or regular positive

600 selection for new variants (Repeated Shifts). In contrast, for II neither the exemplar loci 
601 (HBB and G6PD) nor most of the empirical outliers (Supp Table 3) encode transmembrane

602 proteins, and they show fewer direct ties to the immune system. Therefore, to the extent

603 that Arrested Sweeps reflect selection by infectious agents, the adaptive response appears

604 to compromise basic metabolic cytoplasmic proteins and thus prevent pathogens from

605 rising to overwhelming levels, though perhaps at a cost to the host.

$607 \quad$ Future directions

608 The main goal of this study was to develop and evaluate statistical metrics for

609 detecting malaria-associated signatures of selection. We used the 1000 Genomes as a

610 reliable and comprehensive dataset for this purpose, but future work on additional

611 emerging datasets could further clarify patterns of selection (e.g. GenomeAsia100K

612 Consortium 2019). These tests may be underpowered here due to variants being absent

613 from the dataset, including large indels and copy-number variants, but this issue can be

614 addressed with more complete, high-coverage sets of genotypes. Furthermore, these

615 methods are valid to apply to other species to detect signals of selection driven either by

616 infection or by other factors. Scripts which calculate the statistics presented here are

617 available at https://github.com/jacobtennessen/MalariaHallmarks. The identification and

618 validation of additional examples of functional adaptive polymorphism will allow further

619 refinement of tests for selection, leading to even more discoveries in a fortuitous feedback 
620 loop. In this way, the fields of evolutionary genetics and malaria pathology will continue

621 to bolster each other as they have done for decades.

622

623 Materials and Methods

624

625

Divergent Haplotypes and :

626

For any pair of loci $i$ and $j$ with MAFs $p_{i}$ and $p_{j}$ and joint minor frequency $p_{i j}$ one

627 measure of LD between them (Kelly 1997) is defined as:

628

$$
\delta_{i j}=\frac{\left(p_{i j}-p_{i} * p_{j}\right)^{2}}{p_{i} *\left(1-p_{i}\right) * p_{j} *\left(1-p_{j}\right)}
$$

629

630

The mean LD for a set of $S$ adjacent variants in $n$ sequences (Kelly 1997) is thus:

631

$$
Z_{n S}=\frac{2}{S(S-1)} \sum_{i=1}^{S-1} \sum_{j=i+1}^{S} \delta_{i j}
$$

For a target variant $j$ and the $S-1$ other variants $i$ within distance $g$ bp of $j_{1}$ in $n$

sequences, the statistic Dng or "a ("Dango") is defined here as:

634

635

$$
Q=\sum_{i=1}^{S-1} \delta_{i j}
$$


638 individual populations consistent with panmixia, and not across populations that differ in

639 allele frequencies.

644 balanced polymorphism in the center. " $\mathrm{a}$ is not expected to only detect overdominance,

645 which is only one type of balancing selection, but overdominance is logistically

646 straightforward to simulate. By default, the dominance coefficient was $1 e+06$ and the

647 selection coefficient was 1e-08, yielding nearly identical homozygote finesses of

648 effectively 1 , a heterozygote fitness of $1.01(=1+1 e+06 * 1 e-08)$, and an expected MAF of

649 0.5. We also considered a "skew" scenario with uneven fitnesses: a dominance coefficient

650 of 1.1 and a selection coefficient of 0.1 , yielding homozygote fitnesses of 1 and 1.1 , a

651 heterozygote fitness of 1.11, and an expected MAF of 0.08 . All other polymorphisms were

652 selectively neutral and generated with mutation rate $(\mu)$ of 1 e-7. We simulated either

$65350,000,100,000$, or 200,000 generation of evolution in a population of 10,000 individuals,

654 with population-scaled recombination rate $(\rho)$ set to either 0.01 or 0.001 . We then

655 calculated 'a for the balanced polymorphism, using $g$ ranging from 100 to 5000 bp. As a

656 control, we simulated windows in which all polymorphisms were selectively neutral. These 
657 neutral control windows were $15,000 \mathrm{bp}$, and from each we randomly chose a single

658 variant for which to calculate ${ }^{\circ}$, with MAF $\geq 0.4$ and at least 5,000 bp of sequence on

659 either side. Other parameters matched the selection simulations, with one addition: we

660 also considered a scenario with neutral evolution but a doubled $\mu$ of $2 e-7$, to test if

661 elevated mutation rate alone can be distinguished from a signal of selection. For each

662 distinct set of parameters, we ran 1000 replicate simulations. We quantified overlap

663 between the distributions of simulated windows by finding the lower quantile in

664 selection simulations that matched the equivalent upper quantile of neutral simulations.

666 Application of $\%$

We scanned for " $a$ in YRI in the 1000 Genomes dataset (1000 Genomes Project

668 Consortium 2015), using a distance of $g=500 \mathrm{bp}$. We defined the top 50 candidate genes

669 by ranking all protein-coding genes occurring outside of the HLA region (chromosome 6

670 between 29.7 and $33.1 \mathrm{Mb}$ ) based on $\&$ within exons or within $1 \mathrm{~kb}$ upstream of the gene,

671 under the assumption that these sections are the mostly likely to harbor functional

672 polymorphisms.

673

$674 \quad$ Repeated Shifts and $\Psi$

675 Consider a set of three populations. For $R$ nonoverlapping genomic windows of 676 size $g$ bp, excluding any windows with fewer than two variants, one calculates the highest 
677 Fst among all variants, for each of the three pairwise comparisons. For each pairwise

678 comparison, one then ranks all windows by $\mathrm{F}_{\mathrm{ST}}$, using integers from 1 (highest $\mathrm{F}_{\mathrm{ST}}$ ) to $R$

679 (lowest FST), such that higher FST values are ranked lower. Ties are rounded up; e.g. if the

680 highest F $_{\text {ST }}$ value for a given population pair is observed in two different windows, both

681 windows are assigned a rank of 2 and no window is assigned a rank of 1. Each window

682 thus has three ranks, one for each population pair. For each window, the lowest rank $L$

683 (most extreme F $_{S T}$ ) and the highest rank $H$ (least extreme FST $_{\text {) }}$ are then identified. The

684 statistic $\mathrm{T}_{\mathrm{R}}$ or $\Psi$ ("Trident") is defined as:

685

$$
\hat{\varphi}=\left(\frac{L+H}{2 R}\right)^{2}
$$

Simulations with $\Psi$

691 10,000 diploid individuals to evolve for 14,000 generations, at which point a second

692 population of 5000 individuals is generated from the first one. At 14,500 generations a

693 third population of 5000 individuals is generated from the second one, and all three

694 populations continue to evolve for 500 more generations until the 15,000th generation.

695 We then calculated FST values by randomly sampling 500 individuals per population.

696 Furthermore, we simulated additional windows under the same parameters but with two 
697 adaptive mutations arising at generation 14,750: one in population 1 and one in

698 population 3. For 1000 of these windows we used a selection coefficient of 0.05 , and for

6991000 of these windows we used a selection coefficient of 0.5 . The adaptive mutations

700 occur at different sites in the window and initially appear with 50 copies per population,

701 to minimize the chance that they are lost to drift; this can be thought of as an existing

702 rare neutral mutation suddenly becoming adaptive, or else a novel mutation occurring

703 several generations earlier and reaching an abundance of 50 by generation 14,750. To

704 calculate $\Psi$, we combined each adaptive window with the 10,000 neutral windows one at

705 a time, rather than including all adaptive windows together, to simulate a genome in

706 which the vast majority of windows are neutral. Thus, we could simultaneously evaluate

707 whether the neutral windows behaved neutrally and whether the single adaptive window

708 appeared as an outlier.

709

710 Application of $\Psi$

711 As with Divergent Haplotypes, we scanned the 1000 Genomes dataset for $\Psi$ (1000

712 Genomes Project Consortium 2015). Our populations were Africa, Europe, and Asia. To

713 maximize the signal of local adaptation and minimize admixture, we calculated African

714 allele frequencies from all 504 individuals from the five sub-Saharan African populations

715 (ESN, GWD, LWK, MSL, YRI) and ignored the two diaspora populations (ACB, ASW). For

716 Europe we used all 503 individuals from the five populations (CEU, TSI, FIN, GBR, IBS), and 
717 for East Asia we used all 993 individuals from the ten South Asian and East Asian

718 populations (CHB, JPT, CHS, CDX, KHV, GIH, PJL, BEB, STU, ITU). We used window sizes of

$719 g=5000 \mathrm{bp}$ and $g=50,000 \mathrm{bp}$. We only examined autosomes to avoid the confounding

720 effects of the $\mathrm{X}$ chromosome's unique evolutionary rate impacting $\mathrm{F}_{\mathrm{ST}}$. By default, we

721 aligned windows beginning at the start of each chromosome. However, because windows

722 are nonoverlapping, $\Psi$ is sensitive to how windows are aligned; two closely adjacent

723 variants could be assigned to different windows and thus their shared signal would be

724 missed. Therefore, we also calculated $\Psi$ by starting windows at each 500 bp interval

725 between 0 and 4500 bp from the start of each chromosome. We defined the top 50

726 candidate genes by ranking protein-coding genes according to top $\Psi$ in windows

727 overlapping exons.

729 Arrested Sweeps and II

730 For a given variant with alleles $\mathrm{A}$ and $\mathrm{a}$, one calculates the absolute difference in

731 total heterozygous sites between individuals homozygous for allele $\mathrm{A}\left(H_{A A}\right)$ and

732 individuals homozygous for allele a $\left(H_{a a}\right)$. This difference can be quite large for rare

733 variants, but these are uninteresting with respect to selection; instead, the signal of a

734 sweep is a large difference for a variant that has risen beyond rarity (>1\% frequency).

735 Thus, the difference is multiplied by the MAF, which is calculated across the ingroup and

736 designated $p_{j}$ as above. The product is the heterozygosity difference associated with allele 
$737 \mathrm{~A}, A_{H_{1}}$ for which a high value indicates that one allele is associated with much more

738 nucleotide diversity than the other, a signal of natural selection sweeping away variation

739 in an otherwise polymorphic region:

$$
A_{H}=\left|H_{a a}-H_{A A}\right| * p_{j}
$$

745 formula, but all that matters it the relative, not absolute, value of Fst. Thus, one ranks all

746 ingroup FST values for variants with MAF of $p_{j}$ (rounded to the nearest $1 \%$ in practice), with

747 higher $\mathrm{F}_{\mathrm{ST}}$ values getting lower ranks as with $\Psi$. For each rounded $p_{j .,}$, ranks are divided

748 by the total, yielding an $\mathrm{F}_{\mathrm{ST}}$ rank proportion, $F_{R_{l}}$ which ranges from 0 (high $\mathrm{F}_{\mathrm{ST}}$ ) to 1 (low

$749 \mathrm{~F}_{\mathrm{ST}}$, which is the relevant signal of selection in this scenario). The purifying selection metric

750 is an adjusted reciprocal of MAF in the outgroup, $p_{o_{1}}$ centered around a MAF of $1 \%$. If $p_{0}$

751 is 0 , the adjusted reciprocal is 1 and does not change the final product. If $p_{o}$ is $1 \%$, the

752 adjusted reciprocal is 0.5 . As $p_{0}$ increases above $1 \%$, the adjusted reciprocal rapidly

753 declines, indicating low evidence for an Arrested Sweep. Thus, the measure of a variant

754 showing similar frequencies in the ingroup while excluded from the outgroup, $z$, is:

$$
z=F_{R} *\left(\frac{0.01}{p_{o}+0.01}\right)
$$




$$
\text { II }=A_{H} * Z
$$

761 the total number of heterozygous sites for every possible diploid genome that could be

762 formed from the $2 n$ phased haploid genomes ( $2 n$ choose 2 combinations). In practice,

763 one can assume that the variant does not affect heterozygosity farther away than a given

764 distance $g$ (here set as $1 \mathrm{Mb}$ ) on the same chromosome, and thus heterozygosity can be

765 calculated for a sufficiently large window on either side of the variant, rather than for the

766 entire genome. This calculation can be performed once for a large genomic window (here

767 set as $5 \mathrm{Mb}$ ) and then applied to all variants that are at least $g$ from the edge of the

768 window. For the target variant, one identifies all homozygotes for either allele among the

$7692 n$-choose-2 genomes, and calculates the mean number of heterozygous sites for each,

770 yielding $H_{a a}$ and $H_{A A}$. It is arbitrary which allele is designated as $A$ versus a, and it does not

771 depend on which is derived, dominant, etc. The absolute value of the difference between

$772 H_{a a}$ and $H_{A A}$ is then multiplied by ingroup MAF $p_{j}$ the $F_{\mathrm{ST}}$ rank $F_{R_{l}}$ and the adjusted

773 reciprocal of the outgroup $\mathrm{MAF}_{1}\left(0.01 /\left(p_{0}+0.01\right)\right.$. As with $\&$, this test targets a single

774 panmictic population in order to minimize the effect of population structure on LD. 
778 simulated genomic windows of 2,000,001 bp, with an asymmetrical overdominant

779 balanced polymorphism in the center. As with \&, overdominance is not the only form of

780 balancing selection that II could detect, but it is the representative form used in

781 simulations. We considered "strong" and "weak" selection scenarios. In the "strong"

782 scenario, selection against derived homozygotes was -0.99 and the dominance coefficient

783 was -1, yielding genotype finesses of 1 (ancestral homozygote), 1.99 (heterozygote), and

7840.01 (derived homozygote), and an expected MAF of 0.33. In the "weak" scenario, selection

785 against derived homozygotes was -0.9 and the dominance coefficient was -0.1 , yielding

786 genotype finesses of 1 (ancestral homozygote), 1.09 (heterozygote), and 0.1 (derived

787 homozygote), and an expected MAF of 0.08 . All other polymorphisms were selectively

788 neutral and generated with $\mu$ of 1 e- 7 . We set $\rho$ to 0.001 . We first simulated 10,000

789 generations of neutral evolution in a population of 10,000 individuals, then the outgroup

790 population of 10,000 individuals was generated from the initial population. After another

7912000 generations of neutral evolution, the adaptive mutation was generated in a single

792 sample in the initial population. Unlike with $\Psi$, here it is important for the mutation to

793 first appear in a single individual to generate the change in LD as the rare haplotype

794 rapidly increases in frequency. After 100 additional generations, four new populations of

79510,000 individuals were generated from the initial population to form the ingroup. The

796 simulation then proceeded for 200 more generations to allow the ingroup populations to 
797 diverge. Thus, after a total of 12,300 generations we calculated II for the balanced

798 polymorphism. As a control, we simulated windows in which all polymorphisms were

799 selectively neutral. These neutral controls windows were 2,005,001 bp, and from each we

800 randomly chose a single variant for which to calculate $\mathrm{II}$, with MAF $\geq 0.05$ and at least 1

$801 \mathrm{Mb}$ of sequence on either side. Other parameters matched the selection simulations. In

802 some simulations the target polymorphism was lost to drift while rare, but these were

803 subsequently ignored. For each of the three scenarios (strong selection, weak selection,

804 and neutrality) we examined 1000 replicate simulations in which the target polymorphism

805 was retained.

806

807 Application of II

808 As with the other statistics, we scanned the 1000 Genomes data for II (1000

809 Genomes Project Consortium 2015). We again used YRI as our target population. We used

810 the five sub-Saharan African populations (ESN, GWD, LWK, MSL, YRI) as the ingroup under

811 the assumption that all have experienced similar disease-induced selection. We used

812 Europe (CEU, TSI, FIN, GBR, IBS) as the outgroup. We assumed that only variation within

$813 g=1 \mathrm{Mb}$ was relevant to a given variant. We avoided all sequence within $5 \mathrm{Mb}$ of the

814 centromere on all chromosomes, because unusual levels of polymorphism and LD in these

815 regions could swamp the signal. We only considered variants with $p_{j}$ of at least 0.01 . We

816 defined the top 50 candidate genes using the same criteria as for 8 . 
818 Synthesis

820 values from http://geneontology.org. For all other tests for enrichment, we used Fisher's

821 exact tests. We tested for enrichment in the erythrocyte proteome using the genes

822 detected by Bryk and Wiśniewski (2017). We also compared our top outliers against

823 "erythroid cell" and "erythrocyte" genes on Harmonizome

824 (http://amp.pharm.mssm.edu/Harmonizome; Rouillard et al. 2016), a compilation of text-

825 mining databases of genes and tissues (Santos et al. 2015). To formally test for

826 enrichment, we included the 507 erythroid genes and 1059 erythrocyte genes with a text-

827 mining score over 0.25 , a threshold chosen because all six of our exemplar loci surpass it

828 on both lists (Supp Tables 1, 2, and 3). We also examined higher thresholds to filter out

829 weakly-associated genes and false positives (Figure 5). As a control, we tested for

830 enrichment in four other cell types: hepatocytes, neurons, epithelial cells, and endothelial

831 cells. To look for malaria-associated polymorphisms, we compared our top outliers

832 against the top loci for malaria susceptibility in three independent GWAS, regardless of

833 whether they were significant. The first study (Timmann et al. 2012) reports 50 variants

834 with $p<5 e-05$; we considered all genes within $100 \mathrm{~kb}$ of these variants, excluding genes

835 adjacent to $H B B$ and $A B O$ as these adjacent genes are unlikely to be causal. The second

836 study (Malaria Genomic Epidemiology Network, 2019) reports 97 genomic regions 
837 overlapping variants with a Bayes factor > 1000; we considered all genes within these

838 regions, excluding genes in the regions overlapping $H B B, A B O, G Y P A / B / E$, and $H L A$, other

839 than the exemplar loci themselves, as the other genes in those regions are unlikely to be

840 causal. The third study (Milet et al. 2019) reports 28 genes with $p$ < 1e-05; we considered

841 all of these genes. To look for transmembrane domains, we used TMHMM v. 2.0

842 (Sonnhammer et al. 1998). To look for Plasmodium- or Piroplasm-interacting proteins, we

843 used the curated list of Ebel et al. (2017). To look for low-recombination genes, we used

844 a genetic map (Hirsh et al. 2011) to calculate recombination rate in overlapping windows

845 of $100-200 \mathrm{~kb}$, and we defined low-recombination regions as those averaging less than

$846 \quad 0.01 \mathrm{cM} / \mathrm{Mb}$, which overlap 1054 genes.

Acknowledgements

850 Jonathan Goldberg, Usheer Kanjee, Dan Neafsey, Varshini Odayar, Alexa Rome, Estela

851 Shabani, April Wei, and others. This work was supported by National Institutes of Health

852 grants HL139337 and Al140751.

854 References Cited

8561000 Genomes Project Consortium. 2015. A global reference for human genetic variation.

857 Nature 526(7571):68-74. doi: 10.1038/nature15393 
Aidoo M, Terlouw DJ, Kolczak MS, McElroy PD, ter Kuile FO, Kariuki S, Nahlen BL, Lal AA, Udhayakumar V. 2002. Protective effects of the sickle cell gene against malaria morbidity and mortality. Lancet 359(9314):1311-1312. doi: 10.1016/S0140-6736(02)08273-9

Akey JM. 2009. Constructing genomic maps of positive selection in humans: where do we go from here? Genome Res. 19(5):711-722. doi: 10.1101/gr.086652.108

Allison AC. 1954. Protection afforded by sickle-cell trait against subtertian malarial infection. Br Med J. 1(4857):290-294. doi: 10.1136/bmj.1.4857.290

Andrés AM, Hubisz MJ, Indap A, Torgerson DG, Degenhardt JD, Boyko AR, Gutenkunst RN, White TJ, Green ED, Bustamante CD, et al. 2009. Targets of balancing selection in the human genome. Mol Biol Evol. 26(12):2755-2764. doi: 10.1093/molbev/msp190

Barreiro LB, Quintana-Murci L. 2010. From evolutionary genetics to human immunology: how selection shapes host defence genes. Nat Rev Genet. 11(1):17-30. doi: $10.1038 / \mathrm{nrg} 2698$

Bitarello BD, de Filippo C, Teixeira JC, Schmidt JM, Kleinert P, Meyer D, Andrés AM. 2018. Signatures of long-term balancing selection in human genomes. Genome Biol Evol. 10(3):939-955. doi: 10.1093/gbe/evy054

Bryk AH, Wiśniewski JR. 2017. Quantitative analysis of human red blood cell proteome. J Proteome Res. 16(8):2752-2761. doi: 10.1021/acs.jproteome.7b00025

Cheng X, DeGiorgio M. 2019. Detection of shared balancing selection in the absence of trans-species polymorphism. Mol Biol Evol. 36(1):177-199. doi: 10.1093/molbev/msy202

Chittoria A, Mohanty S, Jaiswal YK, Das A. 2012. Natural selection mediated association of the Duffy (FY) gene polymorphisms with Plasmodium vivax malaria in India. PLoS One 7(9):e45219. doi: 10.1371/journal.pone.0045219

Chung WY, Gardiner DL, Hyland C, Trenholme KR. 2008. Invasion of Rh Null Cells by Plasmodium falciparum identifies a new invasion pathway. Parasitol Res. 102(2):259-263. doi: 10.1007/s00436-007-0756-8

Conte S, Katayama S, Vesterlund L, Karimi M, Dimitriou M, Jansson M, Mortera-Blanco T, Unneberg P, Papaemmanuil E, Sander B, et al. 2015. Aberrant splicing of genes involved in haemoglobin synthesis and impaired terminal erythroid maturation in SF3B1 mutated 
898 refractory anaemia with ring sideroblasts. $\mathrm{Br} /$ Haematol. 171(4):478-490. doi: 10.1111/bjh. 13610

Cowman AF, Tonkin CJ, Tham WH, Duraisingh MT. 2017. The molecular basis of erythrocyte invasion by malaria parasites. Cell Host Microbe. 22(2):232-245. doi: 10.1016/j.chom.2017.07.003

Cserti CM, Dzik WH. 2007. The ABO blood group system and Plasmodium falciparum malaria. Blood 110(7):2250-2258. doi: 10.1182/blood-2007-03-077602

Daron J, Boissière A, Boundenga L, Ngoubangoye B, Houze S, Arnathau C, Sidobre C, Trape J.-F, Durant P, Renaud F, et al. 2020. Population genomic evidence of a Southeast Asian origin of Plasmodium vivax. https://doi.org/10.1101/2020.04.29.067439

DeGiorgio M, Lohmueller KE, Nielsen R. 2014. A model-based approach for identifying signatures of ancient balancing selection in genetic data. PLoS Genet. 10(8):e1004561. doi: 10.1371/journal.pgen.1004561

Ebel ER, Telis N, Venkataram S, Petrov DA, Enard D. 2017. High rate of adaptation of mammalian proteins that interact with Plasmodium and related parasites. PLoS Genet. 13(9):e1007023. doi: 10.1371/journal.pgen.1007023

Fan S, Hansen ME, Lo Y, Tishkoff SA. 2016. Going global by adapting local: A review of recent human adaptation. Science 354(6308):54-59. doi: 10.1126/science.aaf5098 A. 2008. Recessive hereditary methemoglobinemia: two novel mutations in the NADHcytochrome b5 reductase gene. Blood Cells Mol Dis. 41(1):50-55. doi: 10.1016/j.bcmd.2008.02.002

Ferrer-Admetlla A, Liang M, Korneliussen T, Nielsen R. 2014. On detecting incomplete soft or hard selective sweeps using haplotype structure. Mol Biol Evol. 31(5):1275-1291. doi: 10.1093/molbev/msu077 American Drosophila melanogaster show signatures of soft sweeps. PLoS Genet. 
937 Gelabert P, Olalde I, de-Dios T, Civit S, Lalueza-Fox C. 2017. Malaria was a weak selective

938 force in ancient Europeans. Sci Rep. 7(1):1377. doi: 10.1038/s41598-017-01534-5

GenomeAsia100K Consortium. 2019. The GenomeAsia 100K Project enables genetic discoveries across Asia. Nature 576(7785):106-111. doi: 10.1038/s41586-019-1793-z

Gouveia MH, Bergen AW, Borda V, Nunes K, Leal TP, Ogwang MD, Yeboah ED, Mensah JE, Kinyera T, Otim I, et al. 2019. Genetic signatures of gene flow and malaria-driven natural selection in sub-Saharan populations of the "endemic Burkitt Lymphoma belt". PLoS Genet. 15(3):e1008027. doi: 10.1371/journal.pgen.1008027

Hamblin MT, Di Rienzo A. 2000. Detection of the signature of natural selection in humans: evidence from the Duffy blood group locus. Am J Hum Genet. 66(5):1669-1679

Hamblin MT, Thompson EE, Di Rienzo A. 2002. Complex signatures of natural selection at the Duffy blood group locus. Am J Hum Genet. 70:369-383. doi: 10.1086/338628 Buxbaum SG, Akylbekova EL, et al. 2011. The landscape of recombination in African Americans. Nature 476(7359):170-175. doi: 10.1038/nature10336

Jha P, Lu D, Yuan Y, Xu S. 2015. Signature of positive selection of PTK6 gene in East Asian populations: a cross talk for Helicobacter pylori invasion and gastric cancer endemicity. Mol Genet Genomics. 290(5):1741-1752. doi: 10.1007/s00438-015-1032-8

Kang YA, Sanalkumar R, O'Geen H, Linnemann AK, Chang CJ, Bouhassira EE, Farnham PJ,

963 Keles S, Bresnick EH. 2012. Autophagy driven by a master regulator of hematopoiesis. Mol Cell Biol. 32(1):226-239. doi: 10.1128/MCB.06166-11

Kelly JK. 1997. A test of neutrality based on interlocus associations. Genetics 146(3):11979671206.

King CL, Adams JH, Xianli J, Grimberg BT, McHenry AM, Greenberg $\amalg$, Siddiqui A, Howes

970 RE, da Silva-Nunes M, Ferreira MU, et al. 2013. Fy ${ }^{a} / F^{b}$ antigen polymorphism in human 971 erythrocyte Duffy antigen affects susceptibility to Plasmodium vivax malaria. Proc Nat/ 972 Acad Sci U S A. 108(50): 20113-20118. doi: 10.1073/pnas.1109621108

973

974 Laval G, Peyrégne S, Zidane N, Harmant C, Renaud F, Patin E, Prugnolle F, Quintana-Murci 975 L. 2019. Recent adaptive acquisition by African rainforest hunter-gatherers of the late 
976 Pleistocene sickle-cell mutation suggests past differences in malaria exposure. Am J Hum Genet. 104(3):553-561. doi: 10.1016/j.ajhg.2019.02.007

Lee HJ, Georgiadou A, Walther M, Nwakanma D, Stewart LB, Levin M, Otto TD, Conway DJ, Coin LJ, Cunnington AJ. 2018. Integrated pathogen load and dual transcriptome analysis of systemic host-pathogen interactions in severe malaria. Sci Trans/ Med. 10(447):eaar3619. doi: 10.1126/scitransImed.aar3619

983

Leffler EM, Gao Z, Pfeifer S, Ségurel L, Auton A, Venn O, Bowden R, Bontrop R, Wall JD, Sella $G$, et al. 2013. Multiple instances of ancient balancing selection shared between humans and chimpanzees. Science 339(6127):1578-1582. doi: 10.1126/science.1234070

Leffler EM, Band G, Busby GBJ, Kivinen K, Le QS, Clarke GM, Bojang KA, Conway DJ, Jallow $M$, Sisay-Joof $F$, et al. 2017. Resistance to malaria through structural variation of red blood cell invasion receptors. Science 356(6343): eaam6393. doi: 10.1126/science.aam6393

Loy DE, Liu W, Li Y, Learn GH, Plenderleith L, Sundararaman SA, Sharp PM, Hahn BH. 2017. Out of Africa: origins and evolution of the human malaria parasites Plasmodium 994 falciparum and Plasmodium vivax. Int $J$ Parasitol. 47(2-3):87-97. doi: 10.1016/j.jpara.2016.05.008

Mackinnon MJ, Mwangi TW, Snow RW, Marsh K, Williams TN. 2005. Heritability of malaria in Africa. PLoS Med. 2(12):e340.

Malaria Genomic Epidemiology Network. 2015. A novel locus of resistance to severe malaria in a region of ancient balancing selection. Nature 526(7572):253-257. doi:

Malaria Genomic Epidemiology Network. 2019. Insights into malaria susceptibility using genome-wide data on 17,000 individuals from Africa, Asia and Oceania. Nat Commun. 10(1):5732. doi: 10.1038/s41467-019-13480-z

Messer PW. 2013. SLiM: simulating evolution with selection and linkage. Genetics 194(4):1037-1039. doi: 10.1534/genetics.113.152181 
1016 Miller LH, Baruch DI, Marsh K, Doumbo OK. 2002. The pathogenic basis of malaria. Nature 415(6872):673-679. doi: 10.1038/415673a

Modiano D, Luoni G, Sirima BS, Simporé J, Verra F, Konaté A, Rastrelli E, Olivieri A, Calissano C, Paganotti GM, et al. 2001. Haemoglobin C protects against clinical Plasmodium falciparum malaria. Nature 414(6861):305-308

Novotná M, Havlícek J, Smith AP, Kolbeková P, Skallová A, Klose J, Gasová Z, Písacka M, Sechovská M, Flegr J. 2008. Toxoplasma and reaction time: role of toxoplasmosis in the origin, preservation and geographical distribution of Rh blood group polymorphism. Parasitology 135(11):1253-1261. doi: 10.1017/S003118200800485X

O'Reilly-Shah VN, Lynde GC, Jabaley CS. 2018. Is it time to start using the emoji in biomedical literature? Br Med J. 363:k5033. doi: 10.1136/bmj.k5033

Paquette AM, Harahap A, Laosombat V, Patnode JM, Satyagraha A, Sudoyo H, Thompson MK, Yusoff NM, Wilder JA. 2015. The evolutionary origins of Southeast Asian

Pondarre C, Campagna DR, Antiochos B, Sikorski L, Mulhern H, Fleming MD. 2007. $A b c b 7$, the gene responsible for X-linked sideroblastic anemia with ataxia, is essential for hematopoiesis. Blood 109(8):3567-3569. on red blood cell surface modulates Plasmodium vivax invasion of human reticulocytes. Sci Rep. 9(1):8943. doi: 10.1038/s41598-019-45228-6 Harmant C, Lopez M. 2016. Genetic adaptation and Neandertal admixture shaped the immune system of human populations. Cel/ 167(3):643-656.e17. doi: locus statistics. PLoS Genet. 15(6):e1008204. doi: 10.1371/journal.pgen.1008204

Roberti MC, La Starza R, Surace C, Sirleto P, Pinto RM, Pierini V, Crescenzi B, Mecucci C, Angioni A. 2009. RABGAP1L gene rearrangement resulting from a $\operatorname{der}(\mathrm{Y}) \mathrm{t}(\mathrm{Y} ; 1)(\mathrm{q} 12 ; \mathrm{q} 25)$ in acute myeloid leukemia arising in a child with Klinefelter syndrome. Virchows Arch. 454(3):311-316. doi: 10.1007/s00428-009-0732-z 
Rouillard AD, Gundersen GW, Fernandez NF, Wang Z, Monteiro CD, McDermott MG, Ma'ayan A. 2016. The harmonizome: a collection of processed datasets gathered to serve and mine knowledge about genes and proteins. Database (Oxford). 2016:baw100. doi: 10.1093/database/baw100 Gilbert SC, Peschu N, et al. 1995. Natural selection of hemi- and heterozygotes for G6PD deficiency in Africa by resistance to severe malaria. Nature 376(6537):246-249. doi: 10.1038/376246a0.

Sabeti PC, Varilly P, Fry B, Lohmueller J, Hostetter E, Cotsapas C, Xie X, Byrne EH, McCarroll SA, Gaudet R, et al. 2007. Genome-wide detection and characterization of positive selection in human populations. Nature 449(7164):913-918. doi: 10.1038/nature06250. Comprehensive comparison of large-scale tissue expression datasets. PeerJ 3:e1054. doi:

Ségurel L, Thompson EE, Flutre T, Lovstad J, Venkat A, Margulis SW, Moyse J, Ross S, Gamble K, Sella G, et al. 2012. The ABO blood group is a trans-species polymorphism in primates. Proc Natl Acad Sci U S A. 109(45):18493-18498. doi: 10.1073/pnas.1210603109

Ségurel L, Gao Z, Przeworski M. 2013. Ancestry runs deeper than blood: the evolutionary history of $A B O$ points to cryptic variation of functional importance. Bioessays 35(10):862867. doi: 10.1002/bies.201300030

Severance S, Hamza I. 2009. Trafficking of heme and porphyrins in metazoa. Chem Rev. 109(10):4596-616. doi: 10.1021/cr9001116

Shriner D, Rotimi CN. 2018. Whole-genome-sequence-based haplotypes reveal single origin of the sickle allele during the holocene wet phase. Am J Hum Genet. 102(4):547556. doi: 10.1016/j.ajhg.2018.02.003

Siewert KM, Voight BF. 2017. Detecting long-term balancing selection using allele frequency correlation. Mol Biol Evol. 34(11):2996-3005. doi: 10.1093/molbev/msx209 
1095 protoporphyria patients are resistant to growth of malarial parasites. Blood 125(3):534541. doi: 10.1182/blood-2014-04-567149 VM. 2019. MYH9-related disease mutations cause abnormal red blood cell morphology through increased myosin-actin binding at the membrane. Am J Hematol. 94(6):667-677. doi: 10.1002/ajh.25472

Sonnhammer EL, von Heijne G, Krogh A. 1998. A hidden Markov model for predicting transmembrane helices in protein sequences. Proc Int Conf Intell Syst Mol Biol. 6:175-182.

Spurgin LG, Richardson DS. 2010. How pathogens drive genetic diversity: MHC, mechanisms and misunderstandings. Proc Biol Sci. 277(1684):979-988. doi: $10.1098 /$ rspb.2009.2084

Stajich JE, Hahn MW. 2005. Disentangling the effects of demography and selection in human history. Mol Biol Evol. 22(1):63-73. doi: 10.1093/molbev/msh252

Sticova E, Jirsa M. 2013. New insights in bilirubin metabolism and their clinical implications. World J Gastroenterol. 19(38):6398-6407. doi: 10.3748/wjg.v19.i38.6398

Taylor SM, Cerami C, Fairhurst RM. 2013. Hemoglobinopathies: slicing the Gordian knot of Plasmodium falciparum malaria pathogenesis. PLoS Pathog. 9(5):e1003327. doi: 10.1371/journal.ppat.1003327

Tennessen JA, Akey JM. 2011. Parallel adaptive divergence among geographically diverse

Tham WH, Wilson DW, Lopaticki S, Schmidt CQ, Tetteh-Quarcoo PB, Barlow PN, Richard D, Corbin JE, Beeson JG, Cowman AF. 2010. Complement receptor 1 is the host erythrocyte receptor for Plasmodium falciparum PfRh4 invasion ligand. Proc Natl Acad Sci USA. 107(40):17327-17332. doi: 10.1073/pnas.1008151107

Timmann C, Thye T, Vens M, Evans J, May J, Ehmen C, Sievertsen J, Muntau B, Ruge G, Loag $W$, et al. 2012. Genome-wide association study indicates two novel resistance loci for severe malaria. Nature 489:443-446. doi: 10.1038/nature11334 
1134 linkage disequilibrium at human G6PD. recent origin of alleles that confer malarial 1135 resistance. Science 293(5529):455-462.

Vitti JJ, Grossman SR, Sabeti PC. 2013. Detecting natural selection in genomic data. Annu Rev Genet. 47:97-120. doi: 10.1146/annurev-genet-111212-133526

Voight BF, Kudaravalli S, Wen X, Pritchard JK. 2006. A map of recent positive selection in the human genome. PLoS Biol. 4(3):e72.

Weir BS, Cockerham CC. 1984. Estimating F-statistics for the analysis of population structure. Evolution 38(6):1358-1370. doi: 10.1111/j.1558-5646.1984.tb05657.x

White NJ, Pukrittayakamee S, Hien TT, Faiz MA, Mokuolu OA, Dondorp AM. 2014. Malaria. Lancet 383(9918):723-735. doi: 10.1016/S0140-6736(13)60024-0.

WHO. 2019. World malaria report. https://www.who.int/publications-detail/worldmalaria-report-2019 metabolism. J Clin Invest. 124(10):4294-4304. doi: 10.1172/JCI76979 


\section{Supplementary Tables}

Supp Table 1. Top 50 genes based on $\mathrm{a}$ in exons or within $1 \mathrm{~kb}$ upstream, excluding the HLA region, along with the two exemplar loci. $g=500 \mathrm{bp}$.

\begin{tabular}{|l|l|l|l|l|l|}
\hline \multicolumn{1}{|c|}{ Gene } & Chromosome & \multicolumn{1}{c|}{$\boldsymbol{a}$} & Transmembrane $^{\mathbf{a}}$ & \multicolumn{1}{c|}{ Erythrocyte-relevant $^{\mathrm{b}}$} & Malaria GWAS $^{\mathbf{c}}$ \\
\hline ZNF99 & 19 & 34.97 & no & no & no \\
\hline SNX29 & 16 & 34.92 & no & no & no \\
\hline CYP2B6 & 19 & 32.56 & no & E: 0.54 & no \\
\hline TMEM14C & 6 & 28.77 & yes & EC: $0.98 ;$ Prot & no \\
\hline KRTAP9-8 & 17 & 28.47 & no & no & no \\
\hline TNFRSF10D & 8 & 26.81 & yes & no & no \\
\hline MUC4 & 3 & 25.34 & yes & no & no \\
\hline TRAJ36 & 14 & 25.34 & yes & no & no \\
\hline SIRPA & 20 & 23.13 & yes & E: $1.01 ;$ EC: 0.29 & no \\
\hline CYP4F12 & 19 & 22.83 & yes & no & no \\
\hline NCMAP & 1 & 21.72 & yes & no & no \\
\hline ZNF85 & 19 & 21.70 & no & no & no \\
\hline MGAM & 7 & 21.68 & yes & E: 2.25, EC: 0.94 & no \\
\hline CD209 & 19 & 21.62 & yes & no & no \\
\hline PPFIBP1 & 12 & 21.50 & no & no & no \\
\hline IGHV3-23 & 14 & 21.34 & yes & no & no \\
\hline LGALS8 & 1 & 21.04 & no & Prot & no \\
\hline PKD1L1 & 7 & 20.65 & yes & no & no \\
\hline SULT1A1 & 16 & 20.51 & no & no & no \\
\hline IRGM & 5 & 19.92 & no & no & no \\
\hline IGLV3-21 & 22 & 19.29 & yes & no & no \\
\hline
\end{tabular}




\begin{tabular}{|c|c|c|c|c|c|}
\hline CFAP74 & 1 & 19.13 & no & no & no \\
\hline KIR3DL2 & 19 & 19.07 & yes & no & no \\
\hline FAM86C1 & 11 & 18.98 & no & no & no \\
\hline AHNAK2 & 14 & 18.84 & no & no & no \\
\hline IGLV5-48 & 22 & 18.42 & yes & no & no \\
\hline IGLV2-14 & 22 & 18.18 & yes & no & no \\
\hline DHRS2 & 14 & 17.79 & no & E: 0.56 & no \\
\hline MYO15B & 17 & 17.69 & no & $E: 0.28$ & no \\
\hline ORC5 & 7 & 17.31 & no & no & no \\
\hline IGHV1-3 & $14^{\mathrm{e}}$ & 16.69 & yes & no & no \\
\hline CHODL & 21 & 16.55 & yes & no & no \\
\hline IGKV2D-40 & 2 & 16.51 & yes & no & no \\
\hline$Z N F 320$ & 19 & 16.39 & no & no & no \\
\hline FCER2 & 19 & 16.34 & yes & no & no \\
\hline MYOM1 & 18 & 16.31 & no & no & no \\
\hline PGPEP1L & 15 & 16.29 & no & no & no \\
\hline CYB5R3 & 22 & 16.17 & no & E: 1.29 ; Prot & no \\
\hline CLEC4F & 2 & 16.13 & yes & no & no \\
\hline ZNF720 & 16 & 16.13 & no & no & no \\
\hline$\angle R P P R C$ & 2 & 16.09 & no & no & no \\
\hline DMBT1 & 10 & 16.08 & no & no & no \\
\hline MS4A12 & 11 & 15.98 & yes & no & no \\
\hline ORAL1 & $14^{\mathrm{e}}$ & 15.96 & yes & no & BF: 1090 \\
\hline OR51B6 & 11 & 15.87 & yes & no & no \\
\hline$\angle 1 T D 1$ & 1 & 15.87 & no & no & no \\
\hline$A R P C 1 B$ & 7 & 15.77 & no & Prot & no \\
\hline IGHD2-21 & $14^{\mathrm{e}}$ & 15.68 & yes & no & no \\
\hline IGHV1-24 & $14^{\mathrm{e}}$ & 15.66 & yes & no & no \\
\hline
\end{tabular}




\begin{tabular}{|l|l|l|l|l|l|}
\hline$C C D C 158$ & 4 & 15.51 & no & no & no \\
\hline$A B O^{\text {d }}$ & 9 & $10.01^{f}$ & yes & E: $1.74 ;$ EC: 0.59 & BF: $1.2 e+18 ; \mathrm{P}: 4.3 \mathrm{e}-21$ \\
\hline$G Y P A / B / E^{\mathrm{d}}$ & 4 & $7.42^{\mathrm{f}}$ & yes & E: $2.49 ; \mathrm{EC}: 1.70 ;$ Prot & BF: $3.9 \mathrm{e}+07$ \\
\hline
\end{tabular}

avia TMHMM (Sonnhammer et al. 1998)

${ }^{b}$ via text mining (Santoes et al. 2015; Rouillard et al. 2016): $\mathrm{E}=$ score (if over 0.25) for "erythrocyte" \& EC = score (if over 0.25) for "erythroid cell"; or via proteomics (Bryk and Wiśniewski 2017): Prot = in erythrocyte proteome

cevidence in genome-wide association study (GWAS): BF = Bayes factor via Malaria Genomic Epidemiology Network (2019) $\& \mathrm{P}=\mathrm{p}$-value via Timmann et al. (2012)

dexemplar locus

elow-recombination region (Hinch et al. 2011)

fnot in top 50

Supp Table 2. Top 50 genes based on $\Psi$ in exons or within $1 \mathrm{~kb}$ upstream, along with the two exemplar loci. $g=5000 \mathrm{bp}$.

\begin{tabular}{|c|c|c|c|c|c|}
\hline Gene & Chromosome & $\psi$ & Transmembrane $e^{a}$ & Erythrocyte-relevant ${ }^{b}$ & Malaria GWAS \\
\hline PTK6 & 20 & $1.54 \mathrm{e}-08$ & no & no & no \\
\hline SRMS & 20 & $3.42 e-07$ & no & no & no \\
\hline FBX031 & 16 & $8.85 e-07$ & no & no & no \\
\hline SPNS2 & 17 & $9.10 \mathrm{e}-07$ & yes & E: 0.26 & BF: 3020 \\
\hline TTLL 10 & $1^{\mathrm{e}}$ & $1.03 e-06$ & no & no & no \\
\hline IGHG1 & $14^{\mathrm{e}}$ & $7.02 e-05$ & yes & Prot & no \\
\hline SEMA4C & 2 & $8.87 e-06$ & yes & no & no \\
\hline$F A M 178 B$ & 2 & $8.87 e-06$ & no & no & no \\
\hline$M A P 1 L C 3 B$ & 16 & $1.10 \mathrm{e}-05$ & no & Kang et al. 2012 & no \\
\hline $\mathrm{ZCCHC14}$ & 16 & $1.10 \mathrm{e}-05$ & no & no & no \\
\hline$O C A 2$ & 15 & $1.53 e-05$ & yes & no & no \\
\hline$C C D C 92 B$ & 17 & $1.78 \mathrm{e}-05$ & no & no & no \\
\hline PPDPF & 20 & $1.87 e-05$ & no & no & no \\
\hline PRKAG3 & 2 & $2.95 e-05$ & no & no & no \\
\hline
\end{tabular}




\begin{tabular}{|l|l|l|l|l|l|}
\hline GSG1L2 & 17 & $3.11 \mathrm{e}-05$ & yes & no & no \\
\hline SORD & 15 & $3.35 \mathrm{e}-05$ & no & E: $1.17 ;$ Prot & no \\
\hline SLC35F3 & 1 & $3.50 \mathrm{e}-05$ & yes & no & no \\
\hline GLP2R & 17 & $4.54 \mathrm{e}-05$ & yes & no & no \\
\hline TMEM88B & $1 \mathrm{e}$ & $4.94 \mathrm{e}-05$ & yes & no & no \\
\hline ANKRD65 & 1 & $4.94 \mathrm{e}-05$ & no & no & no \\
\hline RSRP1 & 1 & $5.83 \mathrm{e}-05$ & no & no & no \\
\hline RHD & 1 & $5.83 \mathrm{e}-05$ & yes & E: $2.18 ;$ EC: $0.85 ;$ Prot & no \\
\hline BRF1 & 14 & $7.23 \mathrm{e}-05$ & no & no & no \\
\hline MLLT3 & 9 & $7.31 \mathrm{e}-05$ & no & no & no \\
\hline EEFSEC & 3 & $7.76 \mathrm{e}-05$ & no & Prot & no \\
\hline CHRM5 & 15 & $9.22 \mathrm{e}-05$ & yes & no & BF: 1980 \\
\hline SNX20 & 16 & $9.47 \mathrm{e}-05$ & no & no & no \\
\hline GALNT18 & 11 & $1.02 \mathrm{e}-04$ & yes & no & no \\
\hline CNTN2 & 1 & $1.21 \mathrm{e}-04$ & no & no & no \\
\hline SPIN1 & 9 & $1.25 \mathrm{e}-04$ & no & no & no \\
\hline CNNM4 & 2 & $1.35 \mathrm{e}-04$ & yes & no & no \\
\hline HELZ2 & 20 & $1.41 \mathrm{e}-04$ & no & no & no \\
\hline FNDC11 & 20 & $1.41 \mathrm{e}-04$ & no & no & no \\
\hline METTL7B & 12 & $1.41 \mathrm{e}-04$ & yes & no & BF: 1030 \\
\hline ITGA7 & 12 & $1.41 \mathrm{e}-04$ & yes & no & BF: 1030 \\
\hline HERC2 & 15 & $1.50 \mathrm{e}-04$ & no & no & no \\
\hline ANKRD39 & 2 & $1.55 \mathrm{e}-04$ & no & no & no \\
\hline ANKRD23 & 2 & $1.55 \mathrm{e}-04$ & no & no & no \\
\hline ARHGAP26 & 5 & $1.60 \mathrm{e}-04$ & no & no & no \\
\hline CD5 & 11 & $1.60 \mathrm{e}-04$ & yes & E: 0.90 & no \\
\hline MYH9 & 22 & $1.69 \mathrm{e}-04$ & no & Smith et al. 2019; Prot & no \\
\hline MOGS & 2 & $1.73 \mathrm{e}-04$ & yes & Prot & no \\
\hline & & & & & \\
\hline
\end{tabular}




\begin{tabular}{|l|l|l|l|l|l|}
\hline MRPL53 & 2 & $1.73 \mathrm{e}-04$ & no & no & no \\
\hline CCDC142 & 2 & $1.73 \mathrm{e}-04$ & no & no & no \\
\hline PTPRM & 18 & $1.73 \mathrm{e}-04$ & yes & no & P: $3.8 \mathrm{e}-08$ \\
\hline SFTA3 & 14 & $1.74 \mathrm{e}-04$ & no & no & no \\
\hline ADCYAP1R1 & 7 & $1.93 \mathrm{e}-04$ & yes & no & no \\
\hline MYLK4 & 6 & $1.94 \mathrm{e}-04$ & no & no & P: 3.6e-07 \\
\hline TBC1D32 & 6 & $1.99 \mathrm{e}-04$ & no & no & no \\
\hline MRPL20 & $1 \mathrm{e}$ & $2.00 \mathrm{e}-04$ & no & no & no \\
\hline ACKR ${ }^{d}$ & 1 & $4.35 \mathrm{e}-04^{\mathrm{f}}$ & yes & E: $1.99 ;$ EC: $0.34 ;$ Prot & not in the included studies \\
\hline CR ${ }^{d}$ & 1 & $5.65 \mathrm{e}-03^{\mathrm{f}}$ & yes & E: $2.50 ;$ EC: $0.40 ;$ Prot & not in the included studies \\
\hline
\end{tabular}

avia TMHMM (Sonnhammer et al. 1998)

bvia text mining (Santoes et al. 2015; Rouillard et al. 2016): E = score (if over 0.25) for "erythrocyte" \& EC = score (if over 0.25) for "erythroid cell"; or a reference supporting erythroid relevance even without a high text mining score; or via proteomics (Bryk and Wiśniewski 2017): Prot = in erythrocyte proteome

'evidence in genome-wide association study (GWAS): BF = Bayes factor via Malaria Genomic Epidemiology Network (2019) \& $P=$ p-value via Milet et al. (2019)

dexemplar locus

elow-recombination region (Hinch et al. 2011)

fnot in top 50

Supp Table 3. Top 50 genes based on II in exons or within $1 \mathrm{~kb}$ upstream, excluding the HLA region, along with the two exemplar loci.

\begin{tabular}{|l|l|l|l|l|l|}
\hline Gene & Chromosome & II & Transmembrane $^{\text {a }}$ & Erythrocyte-relevant $^{\text {b }}$ & Malaria GWAS $^{\text {c }}$ \\
\hline$R L I M$ & $\mathrm{X}$ & 495.12 & no & no & no \\
\hline$A B C B 7$ & $\mathrm{X}^{\mathrm{e}}$ & 272.91 & yes & E: $0.26 ;$ EC: 1.42 & no \\
\hline$H B B^{\mathrm{d}}$ & 11 & 194.83 & no & E: $2.46 ;$ EC: $2.06 ;$ Prot & BF: $1.8 \mathrm{e}+69 ; \mathrm{P}: 5.6 \mathrm{e}-14$ \\
\hline$U G T 2 B 10$ & 4 & 187.49 & yes & no & no \\
\hline$R A B G A P 1 L$ & $1^{\mathrm{e}}$ & 162.56 & no & EC: $0.86 ;$ Prot & no \\
\hline
\end{tabular}




\begin{tabular}{|l|l|l|l|l|l|}
\hline ZDHHC15 & $\mathrm{X}^{\mathrm{e}}$ & 162.45 & yes & no & no \\
\hline ZKSCAN4 & 6 & 162.19 & no & no & no \\
\hline ZSCAN16 & $6^{\mathrm{e}}$ & 153.98 & no & EC: 0.80 & no \\
\hline ZKSCAN8 & 6 & 153.98 & no & no & no \\
\hline GABBR1 & 6 & 152.81 & yes & no & no \\
\hline OR5V1 & 6 & 143.49 & yes & no & no \\
\hline TARDBP & 1 & 141.49 & no & Prot & no \\
\hline RABGEF1 & $7^{\mathrm{e}}$ & 141.35 & no & Prot & no \\
\hline CSMD3 & 8 & 139.00 & yes & no & no \\
\hline TESK2 & 1 & 136.32 & no & no & no \\
\hline EIF2B3 & 1 & 135.39 & no & Prot & no \\
\hline PRDX1 & 1 & 135.37 & no & E: $0.35 ;$ Prot & no \\
\hline UROD & 1 & 130.54 & no & E: $1.79 ;$ Prot & no \\
\hline HECTD3 & 1 & 130.54 & no & Prot & no \\
\hline MAS1L & 6 & 129.21 & yes & no & no \\
\hline OR2B3 & $6^{\mathrm{e}}$ & 129.07 & yes & no & no \\
\hline ZSWIM5 & 1 & 128.42 & no & no & no \\
\hline ZSCAN12 & $6^{\mathrm{e}}$ & 125.75 & no & no & no \\
\hline KRTAP4-4 & 17 & 125.66 & no & Prot & no \\
\hline DNAH14 & $1 \mathrm{e}$ & 123.89 & no & no & no \\
\hline OIT3 & 10 & 122.99 & no & no & no \\
\hline NKAPL & $6^{\text {e }}$ & 122.91 & no & no & no \\
\hline UGT2B4 & 4 & 122.69 & yes & no & no \\
\hline SLC9C2 & 1 & 122.20 & yes & no & no \\
\hline ABCC12 & 16 & 121.65 & yes & no \\
\hline SPAG16 & 2 & 121.48 & no & no \\
\hline ZSCAN23 & 6 & 121.30 & no & no \\
\hline ZBTB37 & 1 & 119.20 & no & \\
\hline & & & & \\
\hline
\end{tabular}




\begin{tabular}{|c|c|c|c|c|c|}
\hline$S L C 38 A 4$ & 12 & 118.48 & yes & no & no \\
\hline ANKRD45 & 1 & 116.10 & no & no & no \\
\hline KRT32 & 17 & 114.66 & no & Prot & no \\
\hline MOG & 6 & 113.55 & no & no & no \\
\hline CNTLN & 9 & 113.05 & no & no & no \\
\hline QR/CH1 & 3 & 112.89 & no & no & no \\
\hline VKORC1L1 & 7 & 111.13 & yes & Prot & no \\
\hline PLA2G12B & 10 & 106.82 & no & no & no \\
\hline KRTAP2-2 & 17 & 106.65 & no & no & no \\
\hline NIPBL & $5^{e}$ & 105.43 & no & no & BF: 3170 \\
\hline CPLANE1 & 5 & 105.33 & no & no & no \\
\hline MBNL3 & $X$ & 103.46 & no & no & no \\
\hline GPX2 & 14 & 103.42 & no & no & no \\
\hline $\mathrm{RC} 3 \mathrm{H} 1$ & $1^{e}$ & 102.85 & no & no & no \\
\hline KRT35 & 17 & 101.02 & no & Prot & no \\
\hline$K D M 3 A$ & 2 & 100.31 & no & Prot & no \\
\hline KRTAP2-3 & 17 & 99.97 & no & no & no \\
\hline$G 6 P D^{d}$ & $X$ & $68.80^{f}$ & no & E: 2.97; EC: 0.58; Prot & not in the included studies \\
\hline
\end{tabular}

${ }^{a}$ via TMHMM (Sonnhammer et al. 1998)

bvia text mining (Santoes et al. 2015; Rouillard et al. 2016): E = score (if over 0.25) for "erythrocyte" \& EC = score (if over 0.25) for "erythroid cell"; or via proteomics (Bryk and Wiśniewski 2017): Prot = in erythrocyte proteome

cevidence in genome-wide association study (GWAS): BF = Bayes factor via Malaria Genomic Epidemiology Network (2019) \& $P=p$-value via Timmann et al. (2012)

dexemplar locus

elow-recombination region (Hinch et al. 2011)

fnot in top 50 
Supp Table 4. Overlap between outliers in this study and those from other genome-wide scans for selection.

\begin{tabular}{|c|c|c|c|c|c|}
\hline Study & Genes $^{a}$ & Q genes & $\psi$ genes & II genes & Enrichment $^{b}$ \\
\hline $\begin{array}{l}\text { Voight et al. } \\
2006\end{array}$ & 271 & none & MYH9 & CSMD3, DNAH14 & 1.5 \\
\hline $\begin{array}{l}\text { Andrés et al. } \\
2009\end{array}$ & 28 & $\angle G A L S 8$ & none & none & 4.9 \\
\hline $\begin{array}{l}\text { Tennessen and } \\
\text { Akey } 2011\end{array}$ & 1388 & $\begin{array}{lr}\text { ARPC1B, } & \text { CYB5R3, } \\
\text { LRPPRC, } & \text { MUC4, } \\
\text { ZNF99 } & \end{array}$ & $\begin{array}{lr}\text { ARHGAP26, } & \text { CNTN2, } \\
\text { EEFSEC, GLP2R, } & \text { HERC2, } \\
\text { MLLT3, MYH9, OCA2, } & \text { OCT } \\
\text { PTK6, } & \text { PTPRM, } \\
\text { SLC35F3, } & \text { SORD, } \\
\text { ZCCHC14 } & \\
\end{array}$ & $\begin{array}{ll}\text { ABCC12, } & \text { CSMD3, } \\
\text { RC3H1, } & \text { SLC38A4, } \\
\text { ZSWIM5 } & \end{array}$ & $2.4^{* * *}$ \\
\hline $\begin{array}{l}\text { Leffler et al. } \\
2013\end{array}$ & 442 & $D M B T 1, P K D 1 L 1$ & $F B X 031, O C A 2$ & SPAG16 & 1.6 \\
\hline $\begin{array}{l}\text { DeGiorgio et } \\
\text { al. } 2014\end{array}$ & 149 & $\begin{array}{ll}D M B T 1, & \angle G A L S 8, \\
\angle R P P R C, & P K D 1 \angle 1, \\
\text { ZNF85 } & \end{array}$ & MYLK4, SORD & none & $6.3^{* * \star}$ \\
\hline $\begin{array}{l}\text { Ferrer- } \\
\text { Admetlla et al. } \\
2014\end{array}$ & 33 & PKD1L1 & none & none & 4.1 \\
\hline $\begin{array}{l}\text { Siewert and } \\
\text { Voight } 2017\end{array}$ & 1381 & $\begin{array}{l}\text { DHRS2, DMBT1, } \\
M G A M, M Y O 15 B\end{array}$ & $\begin{array}{l}\text { GLP2R, } \\
\text { SLC35F3 }\end{array}$ & $\begin{array}{l}\text { CSMD3, MOG, SPAG 16, } \\
\text { UGT2B4 }\end{array}$ & 1.1 \\
\hline $\begin{array}{l}\text { Bitarello et al. } \\
2018\end{array}$ & 502 & $\begin{array}{l}\text { CCDC158, } \\
\text { IRGPAF12, } \\
\text { NCMAP, ORAL1 }\end{array}$ & $\begin{array}{l}\text { CHRM5, } \\
\text { SLC35F3 }\end{array}$ & none & $2.5^{*}$ \\
\hline $\begin{array}{l}\text { Cheng and } \\
\text { DeGiorgio } \\
2019\end{array}$ & 25 & none & none & SPAG16 & 6.0 \\
\hline
\end{tabular}


${ }^{a}$ Number of reported outlier genes or genes in reported outlier regions. For scans conducted on separate populations, only results from Africans or African Americans are included.

${ }^{b}$ Enrichment for shared genes between our results and each study. ${ }^{*} p<0.05 ; * * x<0.001$ 


\section{Supplementary Figures}
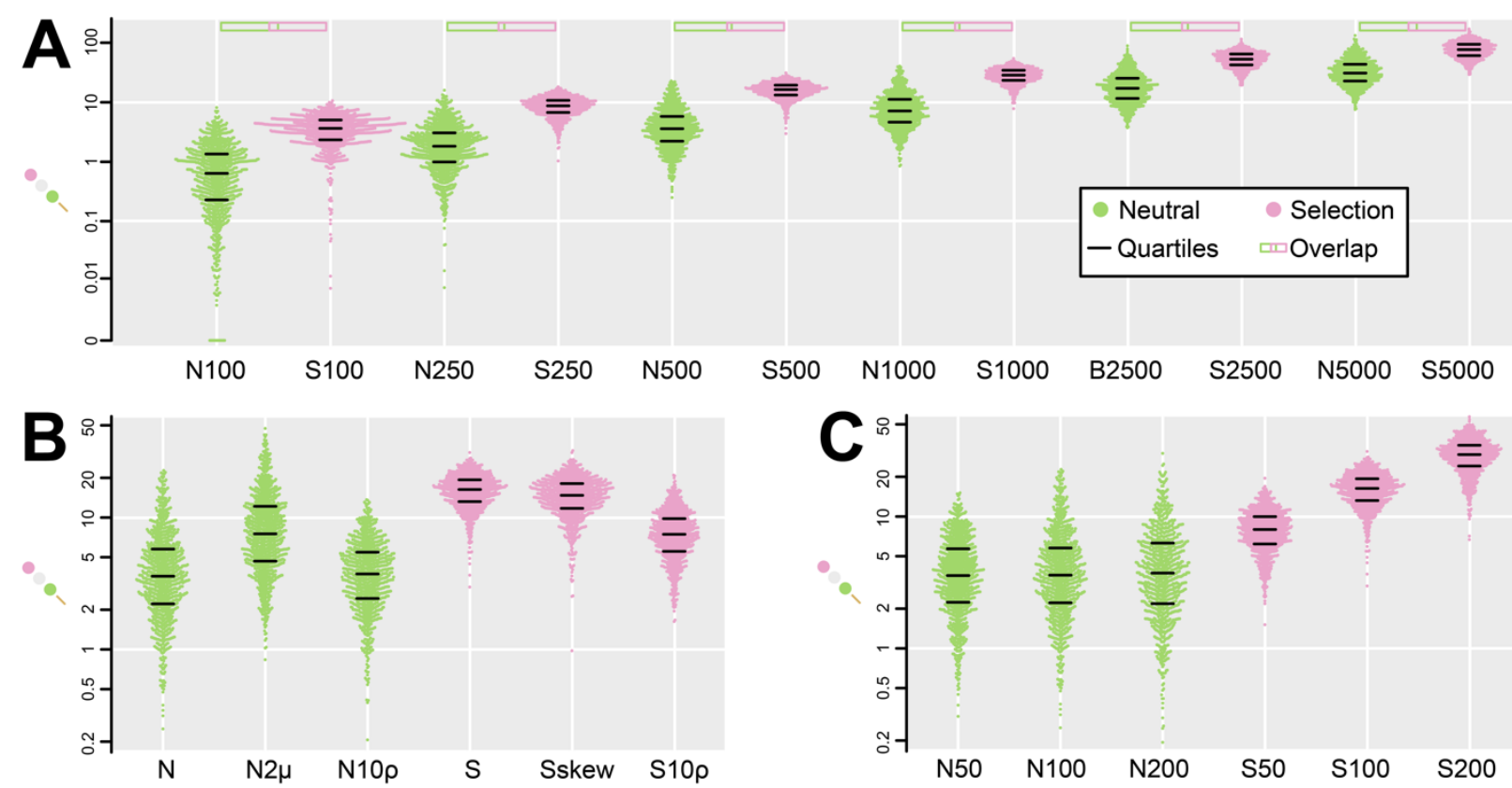

Supplementary Figure 1. Simulation results for "a. (A). Distributions of ${ }^{\circ}$ a values for neutral and selection scenarios with varying $g$ values, with $\rho=0.001$, expected MAF $=0.5, \mu=1 \mathrm{e}-7$, and 100,000 generations. Distributions are labeled N ("neutral") or S ("selection"), along with g value (e.g. N250 = neutral simulations with $g=250 \mathrm{bp}$ ). Boxes above each pair of neutral and selection distributions indicate the degree of overlap between the distributions. Overlap is minimized for intermediate $g$ values of 500 and 1000 bp (lower $7 \% \mathrm{~S}$ quantile meets upper $7 \% \mathrm{~N}$ quantile). (B) Distributions of $\%$ values for neutral and selection scenarios with $g=500$ bp and 100,000 generations. " $\mathrm{N}$ " and " $\mathrm{S}$ " are the same as "N500" and "S500" in (A), and the remaining distributions have the same parameters except for a single alteration each. "N2 $\mu$ " has a doubled mutation rate, "N10 $\rho$ "and "S10 $\rho$ " have 10-fold increased recombination rate, and "Sskew" has expected MAF of 0.08. (C). Distributions of "a values with $g=500 \mathrm{bp}, \rho=0.001$, expected MAF $=0.5, \mu=1 \mathrm{e}-7$, and age of the balanced polymorphism either 50,000 (N50 and S50), 100,000 (N100 and S100) or 200,000 (N200 and S200) generations. 

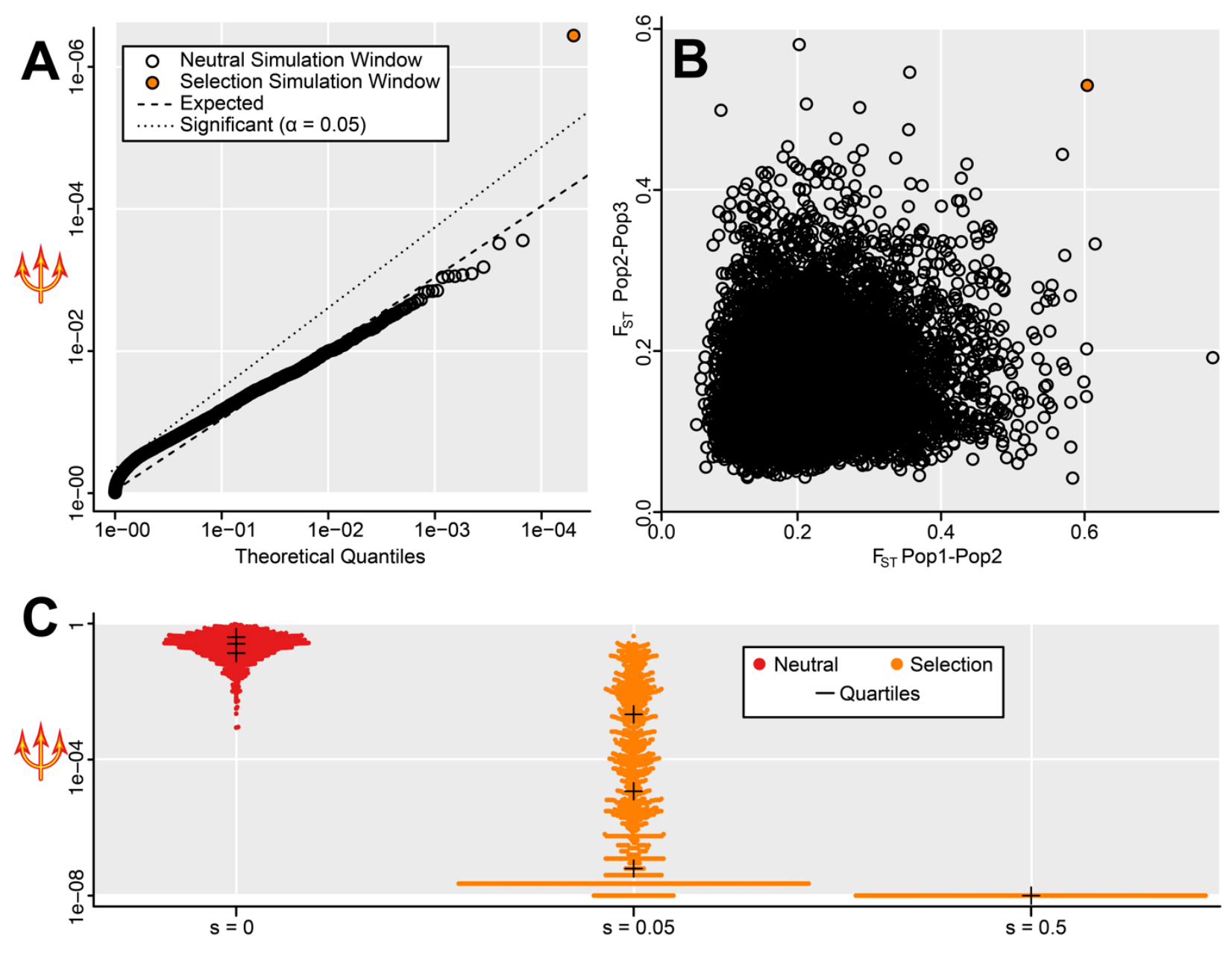

Supplementary Figure 2. Simulation results for $\Psi$. (A) Out of 10,000 neutral windows and a single selection window, the selection window is the clear significant outlier in a QQ plot. (B) In this case, the selection outlier does not show the highest $\mathrm{F}_{\mathrm{ST}}$ in any comparison, yet it is an extreme outlier for $\Psi$ which combines across Fst values. (C) Distribution of $\Psi$ across 1000 windows each with $s$ of $0,0.05$, or 0.5 , when each window is included alone among 10,000 neutral windows. $\Psi$ is substantially lower when selection operates. Every window with $s=0.5$ shows the lowest possible value of $1 \mathrm{e}-08$, so these points are depicted as overlapping rather than fully spread out. 

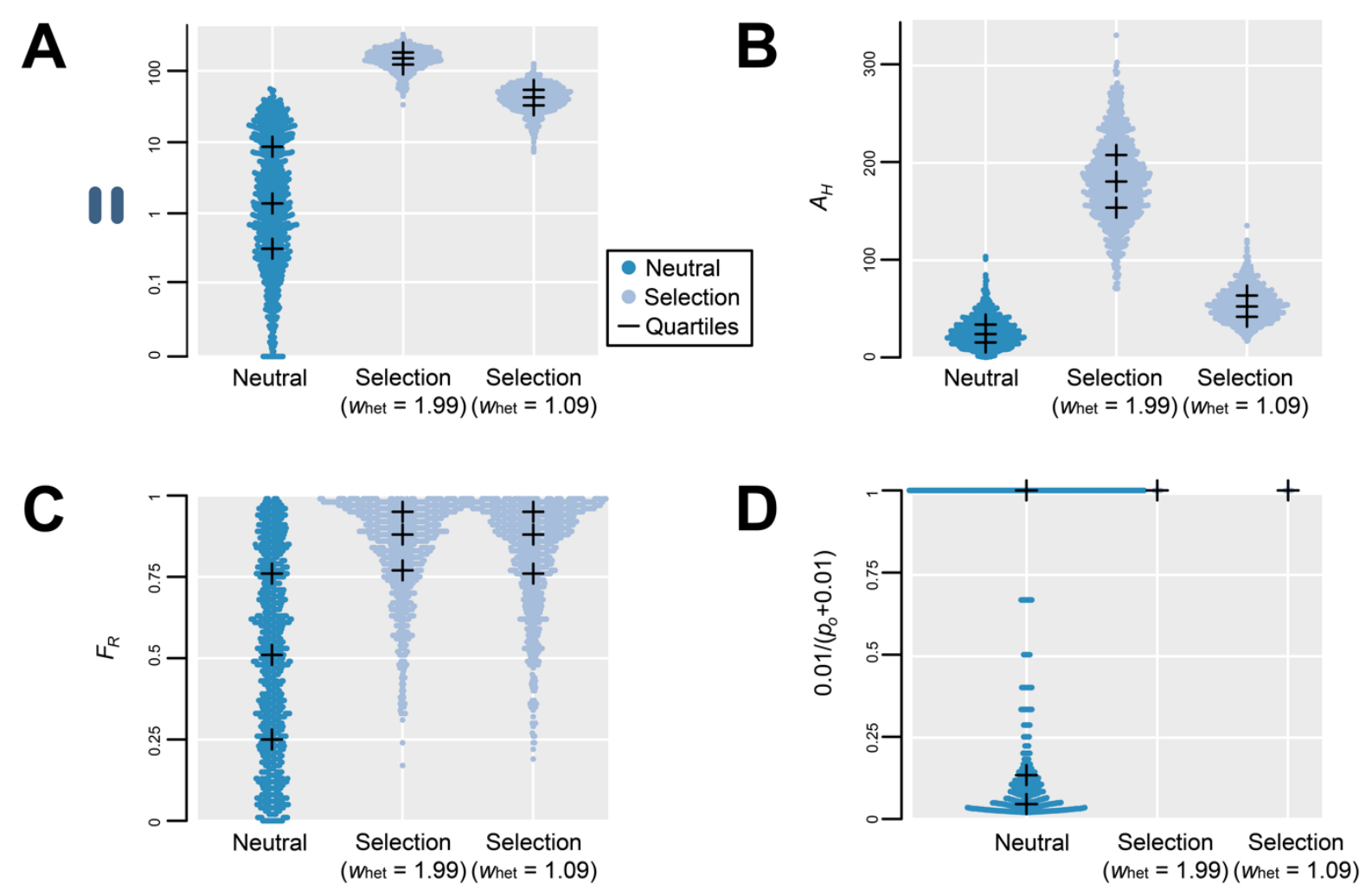

Supplementary Figure 3. Simulation results for II. (A) Distributions of II values for three evolutionary scenarios: neutral evolution, strong selection (heterozygote fitness Whet $=1.99$ ), and weak selection (heterozygote fitness $w_{\text {het }}=1.09$ ). $(B)$ Distributions of the difference in total heterozygous sites times ingroup allele frequency $\left(A_{H}\right)$ for the same evolutionary scenarios. (C) Distributions of $\mathrm{F}_{\mathrm{ST}}$ rank proportion $\left(F_{R}\right)$ for the same evolutionary scenarios. (D) Distributions of the adjusted reciprocal of the outgroup allele frequency $\left(0.01 /\left(p_{o}+0.01\right)\right.$ for the same evolutionary scenarios; selection scenarios are always at one because $p_{o}$ is zero, so datapoints are overlapped for ease of visualization. 